7-15-2021

\title{
Beyond Degrees: Longer Term Outcomes of the Kalamazoo Promise
}

\author{
Brad J. Hershbein \\ W.E Upjohn Institute for Employment Research, hershbein@upjohn.org \\ Isabel McMullen \\ W.E. Upjohn Institute for Employment Research, mcmullen@upjohn.org \\ Brian Pittelko \\ W.E. Upjohn Institute for Employment Research, Pittelko@upjohn.org \\ Bridget F. Timmeney \\ W.E. Upjohn Institute for Employment Research, timmeney@upjohn.org \\ Upjohn Author(s) ORCID Identifier: \\ (D) https://orcid.org/0000-0002-2534-8164 \\ (iD) https://orcid.org/0000-0002-1831-7175
}

Upjohn Institute working paper ; 21-350

Follow this and additional works at: https://research.upjohn.org/up_workingpapers

Part of the Labor Economics Commons

\section{Citation}

Hershbein, Brad J., Isabel McMullen, Brian Pittelko, and Bridget F. Timmeney. 2021. "Beyond Degrees: Longer Term Outcomes of the Kalamazoo Promise." Upjohn Institute Working Paper 21-350. Kalamazoo, MI: W.E. Upjohn Institute for Employment Research. https://doi.org/10.17848/wp21-350 


\title{
W.E.UPJOHN INSTITUTE
}

\section{Beyond degrees: Longer term outcomes of the Kalamazoo Promise}

\author{
Upjohn Institute Working Paper 21-350 \\ Brad Hershbein, Isabel McMullen, Brian Pittelko, and Bridget Timmeney \\ W.E. Upjohn Institute for Employment Research \\ e-mail: hershbein@upjohn.org
}

July 2021

\begin{abstract}
We estimate the effects on workforce and location outcomes of the Kalamazoo Promise, a generous, place-based college scholarship. Drawing upon administrative unemployment insurance wage records merged with individual-level education data, we identify Promise effects by comparing eligible to ineligible graduates before and after the Promise's initiation. We supplement this quantitative analysis with surveys and interviews. Despite earlier research showing that the Kalamazoo Promise substantially increased degree attainment, we find little evidence that the program affected average earnings within 10 years of high school graduation. However, the Kalamazoo Promise may have increased the likelihood of eligible graduates having earnings, within Michigan, in the middle of the distribution. We discuss the possible role of job availability in understanding these patterns and the implications for free-tuition college programs as a workforce development tool.
\end{abstract}

JEL Codes: I21, I22, I24

Key Words: place-based scholarship, difference-in-differences, mixed methods, workforce outcomes, earnings, migration, education policy

Affiliations and Acknowledgements: Brad Hershbein (corresponding author) is a senior economist, Isabel McMullen is a senior research analyst, Brian Pittelko is a senior research analyst, and Bridget Timmeney is a special projects coordinator, all at the W.E. Upjohn Institute for Employment Research. The corresponding author can be reached at hershbein@upjohn.org.

We thank Tim Bartik, Michelle Miller-Adams, conference participants at the Association for Education Finance and Policy and Association for Public Policy and Management meetings, and seminar participants at the Upjohn Institute. We are grateful to Bob Jorth of the Kalamazoo Promise, Michael Rice of Kalamazoo Public Schools (KPS), and the Michigan UIA for assistance and providing data. We also thank the Strada Foundation for its generous support of this project and the Promise Research Consortium. Zach Brown provided valuable research assistance. The authors have no material interests in this research, although McMullen and Pittelko receive financial support from the Kalamazoo Promise. All errors are our own. 
The analysis uses confidential student-level data obtained with permission from KPS, the Kalamazoo Promise, and the Michigan Unemployment Insurance Agency; we are unable to publicly share these data. Interested researchers who want to use these data would need to enter into separate contracts with these organizations. The authors would provide guidance on the structure of such contracts (corresponding author: hershbein@upjohn.org).

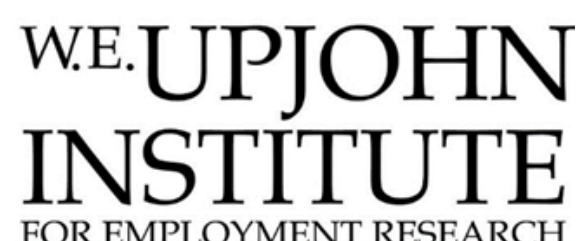

FOR EMPLOYMENT RESEARCH

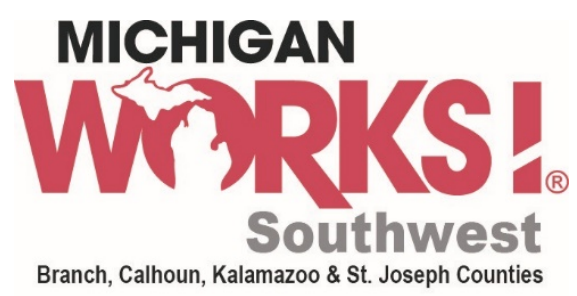

Upjohn Institute working papers are meant to stimulate discussion and criticism among the policy research community. Content and opinions are the sole responsibility of the author. 


\section{INTRODUCTION}

Within the past 15 years, place-based college scholarships have become increasingly common throughout the country. Unlike traditional merit or need-based scholarship programs, place-based college scholarships often have fewer eligibility requirements, are tied to geography at a substate level, and have motives of promoting both educational attainment and local workforce development (Miller-Adams 2015). This form of financial aid can now be found in nearly 200 communities across the country (Miller-Adams et al. 2020). However, the effectiveness of place-based scholarships in meeting these goals is predicated on their increasing students' educational attainment as well as improving their employment and earnings. Despite the rapid dissemination of these programs, which vary considerably in their structure, research has just begun to assess their effectiveness in achieving the first goal, with mostly positive results. Research on the second objective - improving labor market outcomes— has been harder to come by, in part due to the longer horizon needed for evaluation. ${ }^{1}$

In this paper, we examine labor market impacts of the Kalamazoo Promise, one of the earliest and most generous place-based college scholarships. Since 2006, the Kalamazoo Promise has provided up to 100 percent of tuition and fees—in "first-dollar" terms before other financial aid - at any public college or university in Michigan to graduates of the Kalamazoo school district. The program is universal in that graduates are eligible if they live within the district and have attended since ninth grade — there are no merit or financial need requirements. Previous research has found that the program substantially increased college enrollment and college

\footnotetext{
${ }^{1}$ The research here represents one project of the Promise Research Consortium, an effort funded by a competitive grant from the Strada Foundation to study workforce outcomes of place-based college scholarships in four communities: Kalamazoo; Knox County, Tennessee; Pittsburgh, and Denver.
} 
completion (Bartik, Hershbein, and Lachowska 2020). To understand whether these boosts in education translate into improved employment and earnings, we merge individual-level administrative education records with quarterly wage records from Michigan's Unemployment Insurance (UI) system. We then compare, using difference-in-differences, outcomes between individuals eligible and ineligible for the Promise, for cohorts before and after the program was in place.

Despite finding in an earlier paper that the Kalamazoo Promise increased degree attainment by between one-quarter and one-third (Bartik, Hershbein, and Lachowska 2020), our current results show that these education gains do not appear to translate into clearly improved employment and earnings. We find essentially no change in the likelihood that a Promise-eligible individual was employed in Michigan up to 10 years after their high school graduation, and this holds for different definitions of employment intensity. Although our estimates are somewhat imprecise, at the upper bound, we can reject that the Promise increased year-round employment rates (employment in four consecutive quarters) by 8 percentage points $7-10$ years after high school graduation, relative to a mean of about 30 percent. We also find little effect on average earnings levels, whether we condition on employment or not. Our point estimates for average quarterly earnings within the first six years after high school graduation are small and negativeconsistent with increased college enrollment - and although they turn positive at the 7-10-year horizon, they remain modest and below conventional levels of statistical significance.

Because the conditional mean may mask important effects at other parts of the earnings distribution, we also estimate impacts on the likelihood that earnings exceed various thresholds. We find Promise-eligible individuals are about 5 percentage points (roughly 6-7 percent) more likely to have average quarterly earnings above a range of $\$ 4,500-\$ 8,500$, conditional on having 
positive earnings, although these estimates are somewhat imprecise and just miss conventional statistical significance levels. However, when we don't condition on positive earnings and instead look over all graduates, we find similar positive impacts that are statistically significant. These patterns together suggest the Promise did have some impact on shifting the earnings distribution upward.

Given the joint economic development goals of place-based scholarships, we also investigate whether the Kalamazoo Promise affected individuals' location choices (conditional on being within Michigan). We find that, 4-10 years after high school, Promise-eligible individuals were approximately 15 percentage points (18 percent) more likely to live within 10 miles of downtown Kalamazoo than previous cohorts, and this impact is robust and statistically significant.

Taken as a whole, our results show mixed impacts of the Kalamazoo Promise as a strategy for local economic development. Although eligible individuals increased their degree attainment and are more likely to stay in the local area-boosting the share of young, educated residents - their employment and earnings prospects have not significantly changed —at least not to date. As we discuss below, this pattern of findings contrasts somewhat with other emerging research into longer-term outcomes of place-based scholarships. It suggests, however, that programs that increase educational attainment may not be sufficient, by themselves, to also increase economic mobility. 


\section{LITERATURE REVIEW}

The literature on college scholarships is rather voluminous, and we focus here on describing the most salient studies both for place-based scholarships and longer-term (beyond college-going) outcomes. ${ }^{2}$

Although few of the nearly 200 place-based college scholarships have been studied, and there is doubtless some study bias toward larger, more generous, and more prominent programs, research to date has found positive impacts on enrollment and, for more mature programs, often degree completion as well. For example, using two forms of difference-in-differences, Bartik, Hershbein, and Lachowska (2020) found that the Kalamazoo Promise increased overall enrollment by $7-9$ percentage points, bachelor's degree completion within six years by $7-8$ percentage points, and any credential completion within six years by $10-12$ percentage points. ${ }^{3}$ Swanson and Ritter (2020), studying the El Dorado (AR) Promise, which closely resembles the Kalamazoo scholarship in most features, found similar impacts on both enrollment and degree completion. Interestingly, both of these studies found effects on low-income students and students of color at least as large as those for higher-income or white students.

Programs that include some merit requirements or provide funding only for community colleges have also been found to increase college enrollment. The Pittsburgh Promise, for instance, which has a modest GPA requirement, increased four-year college enrollment for most demographic groups (Page and Iriti 2016). Additionally, the Knox Achieves community and technical college program, the forerunner to the statewide Tennessee Promise, increased

\footnotetext{
${ }^{2}$ Deming and Dynarski (2010) and Page and Scott-Clayton (2016) offer excellent reviews of recent scholarship of grant and loan assistance policies on college success.

${ }^{3}$ Bartik, Hershbein, and Lachowska (2020) also summarize research of place-based scholarships on K-12 enrollment and academic performance, migration, and housing prices.
} 
community college enrollment and accumulated college credits, with only slight substitution from the four-year college sector (and that diminished over time; Carruthers and Fox 2016).

Thus, place-based college scholarships, at least the ones studied, can increase measurable human capital — perhaps the a priori litmus test for their potential to increase employment and earnings. In turn, increases in earnings are the most likely channel through which such programs could pay for themselves and deliver net social returns (or a marginal value of social funds; Hendren and Sprung-Keyser 2020). ${ }^{4}$ As these programs continue to proliferate and "free-tuition" college receives growing consideration from policymakers and the public, benefit-cost calculations become integral, but the data necessary to make them are often lacking. Indeed, several papers have made assumptions for how marginal increases in degree attainment translate to later earnings, which generally cannot be observed, at least not over the entire career. Bartik, Hershbein, and Lachowksa (2016), for example, make various assumptions about earnings profiles by demographic group and education level, in conjunction with the costs of the scholarship, to estimate an internal rate of return for the Kalamazoo Promise as high as 11 percent. Angrist, Autor, and Pallais (2020) apply estimates of the causal return to degree attainment on earnings to simulate earnings profiles of beneficiaries of the Susan Thompson Buffett Foundation scholarships in Nebraska, finding that projected earnings gains exceed program costs for most groups.

Studies that examine direct impacts of scholarships on employment and earnings are rarer, often requiring difficult administrative data linkages and sufficient time to elapse for such outcomes to be meaningful. Due to the relative recency of place-based scholarships, very few

${ }^{4}$ Place-based scholarships vary in their funding source: some are private, some are public, and some are both (see Miller-Adams et al. 2020), hence, the broadening of Hendren and Sprung Keyser's "public" funds to "social" funds. 
such studies exist. Even studies of workforce outcomes from merit-based and need-based scholarships are not common. Two notable examples are longer-term evaluations of the West Virginia Promise, a state merit-based program, and the Cal Grant, California's need- and meritbased financial aid program. For the first, Scott-Clayton and Zafar (2019) used matched state UI wage records and credit bureau data to conclude that, by their late 20 s, individuals that had been eligible for the scholarship had better credit outcomes and financial health, were more likely to be homeowners and live in higher-income neighborhoods, and had 7 percent higher earnings, conditional on employment, although this last estimate was imprecise. For the Cal Grant, Bettinger et al. (2019) matched federal tax data to state records and found that annual earnings were about 5 percent higher among Cal Grant recipients, although this estimate was also imprecise. Interestingly, the West Virginia Promise mostly accelerated degree completion rather than raising its rate, whereas the Cal Grant did modestly raise degree completion (although by a much smaller amount than in Kalamazoo).

Recent work by Black et al. (2020) looked at long-term impacts not of a scholarship but of exogenous increases in federal loan limits. While this increase in liquidity is not strictly comparable to the additional income transfer of grant aid, the comparisons are still illustrative. Using matched education and UI wage records in Texas, they found higher borrowing limits led to greater degree attainment, higher earnings, and decreasing student loan default 8-12 years after high school graduation. Denning, Marx, and Turner (2019), using similar data, examine the impact of eligibility for Pell Grants with a regression-discontinuity design and find that, among first-time students near the cutoff, those with automatic eligibility for the Grant are more likely to graduate and have higher earnings seven years after enrollment. In both cases, the magnitude of these increases, given the size and type of the policy change, is large relative to the West 
Virginia and California studies, suggesting geographical differences in labor markets may play a role in later outcomes. ${ }^{5}$

The study that most resembles the analysis in this paper is Carruthers, Fox, and Jepson (2020)'s ongoing research on the Knox Achieves program, a place-based, last-dollar community college scholarship in Knox County, Tennessee. Using matched UI wage records from the state, they document increased associate degree attainment and an increase in in-state earnings of recipients by their mid-20s. Since the return to a bachelor's degree is even greater than that for an associate degree (Zimmerman 2014), we might expect earnings to increase even more from the Kalamazoo Promise, but the geographic disparities mentioned above may still be salient. ${ }^{6}$ Thus, it is important to know the geographic context of the Kalamazoo Promise.

\section{KALAMAZOO PUBLIC SCHOOLS AND THE KALAMAZOO PROMISE}

Kalamazoo Public Schools (KPS) is a mostly urban, mid-sized school district in southwest Michigan. Like many urban districts, KPS has relatively high poverty, and between 65 and 70 percent of students in any given year receive free or reduced-price lunch. The district also has a high proportion of racial minorities, about 65 percent, split across Blacks (39 percent), Hispanics (14 percent), and other (including multiracial) groups (11 percent). These rates are all substantially higher than neighboring suburban districts (MI School Data 2021). Unusual among

${ }^{5}$ Chakrabarti, Nober, and van der Klaaw (2020) and Chakrabarti, Gorton, and Lovenheim (2020) leverage National Student Clearinghouse data and credit bureau data and show, respectively, that state merit aid programs decrease student and overall debt by the time individuals are in their late $20 \mathrm{~s}$, and that greater state appropriations for public colleges effectively reduce tuition and lead to less debt for four-year college students and more degree completion and less subsequent default for two-year college students.

${ }^{6}$ The current study, the Carruthers, Fox, and Jepson (2020) study, and two more that are ongoing for the Pittsburgh Promise and the Denver Scholarship Fund are part of a competitive grant from Strada Foundation to investigate workforce impacts of place-based scholarships. The four programs differ in their features, but they collectively represent the first set of analyses of place-based scholarships on longer-term impacts on individuals. 
similar urban districts in Michigan, however, which have generally lost enrollment over the past 15 years, KPS has grown from around 10,000 students when the Kalamazoo Promise was announced to just shy of 13,000 students during the 2019-2020 school year (MI School Data 2021). ${ }^{7}$ Commensurately, the number of annual graduates, across two mainline and one alternative high schools, has edged up recently from approximately 500 before the scholarship to roughly 700 today. ${ }^{8}$

Announced in November 2005 and taking effect for the high school class of 2006, the Kalamazoo Promise (henceforth, Promise) is a scholarship available to all students who graduate from KPS, reside in the district, and have been continuously enrolled since the beginning of high school. Unlike most student aid, the Promise has neither merit requirements (high school GPA or test scores) nor financial need requirements. According to the donors who anonymously fund the scholarship, the Promise's purpose is to improve KPS, attract people to Kalamazoo, and increase local college graduates, which should improve workforce outcomes (Miller-Adams 2015). Entering its sixteenth year of operation in 2021, the scholarship has awarded over $\$ 130$ million dollars to over 6,000 individual students.

A unique feature of the Promise is its simplicity and generosity. To apply for the Promise, seniors complete a one-page form asking basic contact information and only a halfdozen questions. Eligibility is based on residency and enrollment in the district. Students continuously enrolled since the beginning of ninth grade receive first-dollar funding (applied before any other financial aid) of 65 percent of tuition and fees at any public college or

\footnotetext{
${ }^{7}$ Bartik, Eberts, and Huang (2010) and Hershbein (2013) provide evidence that this enrollment growth was in fact caused by the Kalamazoo Promise.

${ }^{8}$ High school graduation rates have also increased, but this seems to be a secular phenomenon experienced by similar districts throughout the state. An earlier draft of Bartik, Hershbein, and Lachowska (2020) compared such Michigan districts and found no detectable impact of the Promise on graduation rates.
} 
university in Michigan. ${ }^{9}$ This share increases on a sliding scale with each additional earlier grade of KPS enrollment, reaching 100 percent for students enrolled continuously from kindergarten. To maintain eligibility, students enrolled in a postsecondary institution must be enrolled full-time (except for attendance at the local community college, where the requirement is half-time attendance) and maintain a 2.0 GPA. There are no other financial need or academic merit requirements. The funding is available up to 130 credits, a bachelor's degree, or 10 years after high school, whichever comes first.

\section{DATA AND METHODS}

We draw upon multiple administrative data sources to analyze the impacts of the Promise on workforce outcomes of KPS graduates. In order to allow sufficient time for these outcomes to be meaningful, we focus on cohorts from the classes of 2003 through 2013.

\section{A. KPS and Promise Data}

Our information on individual students comes from KPS, the Kalamazoo Promise, and the National Student Clearinghouse. In addition to covering demographics, high school academics, and college enrollment, these data allow us to implement our difference-indifferences identification strategy. More specifically, while we observe Promise eligibility directly for graduating classes of 2006 and later, when the Promise was in effect, we need to assign "pseudo-eligibility" for earlier cohorts for whether they would have been eligible had the Promise been around at that time. KPS records provide a history of student enrollment and

\footnotetext{
${ }^{9}$ Since 2015, the scholarship can be applied at most private colleges and universities within Michigan, with the Promise paying the equivalent tuition rate of the University of Michigan and the private college agreeing to pay the difference. Additionally, Promise funds can now be applied toward certain non-credential training programs, such as apprenticeships. These changes occurred after the cohorts we study in this paper.
} 
residency in the district, which allows us to construct a binary Promise eligibility indicator for students in earlier cohorts who would have been eligible, according to the rules, had the Promise existed for them. Data limitations prevent us from ascertaining the exact fractional scholarship for some of the pre-Promise cohorts, and so, as in previous research, we discretize eligibility between those with at least a 65 percent scholarship and those with zero scholarship. (For more details on these data, see Bartik, Hershbein, and Lachowksa 2020 and the web appendix thereof. $)^{10}$

Table 1 shows the number of KPS graduates from the district's two mainline and one alternative high school from the classes of 2003 through 2013. The middle column shows the count of Promise-eligible graduates (or that would have been eligible if the Promise had existed in the past), and the third column shows the count of Promise-ineligible graduates. ${ }^{11}$ Appendix Table A1 shows demographic summary statistics (taken from Bartik, Hershbein, and Lachowska 2020) of the sample, by eligibility status and policy regime.

\section{B. Unemployment Insurance Wage Data}

Workforce data from Michigan's Unemployment Insurance Agency (UIA), which cover payroll employment in the state, allow us to follow KPS graduates into the labor market. These data contain records on earnings from each covered employer an individual worked for in a given calendar quarter, the NAICS industry code of the employer, and the ZIP code of both the

\footnotetext{
${ }^{10}$ As noted in Bartik, Hershbein, and Lachowksa (2020), the observed administrative eligibility data from the Promise do not perfectly match rules-based eligibility based on KPS attendance history largely because the Promise administratively granted exceptions to some higher-risk students. A series of robustness checks, from dropping individuals with disputed status, to reweighting on observables, to instrumenting actual eligibility with rules-based eligibility, did not materially affect college-going outcomes.

${ }^{11}$ As perhaps is not surprising for a universal scholarship, more than 85 percent of graduates in these cohorts were eligible for the Promise.
} 
worker's residence and of the business payroll office (from which we can derive the individual's proximity to Kalamazoo).

Unfortunately, unlike Tennessee, Texas, and a few other states that have well-established longitudinal data systems connecting educational and workforce records, Michigan's system is still nascent, and obtaining the UI data required a special matching request to UIA. That agency conducted the match based on individual records we securely submitted to them, returning to us records spanning the first quarter of 2006 (the earliest quarter that could be matched) through the first quarter of 2019. This time range permits us to examine workforce outcomes up to 10 years after high school graduation for the pre-Promise and first few post-Promise cohorts, although it does preclude us from looking at Promise impacts immediately after high school (as data for the pre-Promise cohorts are not available).

Table 2 shows match rates by cohort, both at the individual level (left section) and by the maximum possible number of post-high-school-gradation calendar quarters (right section). ${ }^{12}$ Overall, we were able to match 79.2 percent of all KPS graduates to the UI data, with this share increasing across cohorts. Conditional on ever being matched, individuals' average match rate across all post-high-school-graduation calendar quarters is more stable across cohorts, at just under two-thirds.

There are several reasons why match rates do not reach 100 percent. To be included in the UI data, an individual must work at a job in the state of Michigan covered by UI. While the coverage universe includes most employees, it notably excludes some groups, such as the selfemployed (including independent contractors and online platform workers) and those working for the federal government (including the military). Based on calculations from the American

\footnotetext{
${ }^{12}$ Appendix Table A2 shows match rates broken down by presumed eligibility and cohort.
} 
Community Survey (ACS), roughly 3-4 percent of Kalamazoo-area 19-30 year-olds are selfemployed, and another 1 percent work for the federal government. The other significant group that lacks coverage in the data are those who work outside the state - either commuters or migrants. Between 3-5 percent of the same age group leave Michigan annually, according to the ACS. Thus, we might expect between one-third and one-half of the unmatched to be out of coverage, but possibly employed, but the most likely reason for the remaining unmatched (including in a given quarter but matched overall) is that the individual isn't working.

Overall match rates are noticeably lower for pre-Promise cohorts (2003-2005), at roughly 56 percent, than for Promise cohorts, which are all above 80 percent. This matching gap persists consistently with time elapsed since graduation, as shown in Figure $1 .{ }^{13}$ The differential match rates are potentially problematic for the difference-in-differences approach we use, described below, but several factors should at least partially mitigate any concerns.

First, based on conversations with representatives from Michigan's UI agency, the matching procedure used, which relies on a name and date-of-birth bridge to Social Security Number (SSN) via driver's license and state IDs, is incomplete before 2006, the year our data begin and, coincidentally, the beginning of the Promise. ${ }^{14}$ As shown in Appendix Table A2, the match rate is lower among pre-Promise cohorts for both presumed-eligible and presumedineligible students, and the differential in match rates between the two eligibility groups is similar before and after the Promise. This is at least consistent with a missing at random assumption.

${ }^{13}$ The sharp jumps and falls in early quarters in Figure 1 are consistent with college enrollment (which we confirm in our education data) and summer jobs. The increase in matching across Promise cohorts is consistent with the economic recovery following the Great Recession. For the hiring difficulties faced by young people, especially, in a recession, see Forsythe (2019).

${ }^{14}$ Michigan does not use SSNs for educational records, and the state developed a crosswalk to develop its student longitudinal data system. However, priority in matching was given to more recent cohorts. 
Second, the demographic and academic characteristics of matched individuals are generally quite similar to those of the entire sample of high school graduates. Table 3 shows that gender, racial, socioeconomic, and high school differences are no more than a few percentage points. On the other hand, there is a negative gradient with high school GPA, with academically stronger students being slightly less likely to match overall and even less so when weighted by quarters since high school. Table 3 also shows the distribution of college start behavior. Student who don't start college within 12 months of high school graduation are slightly less likely to be matched, as are students who start college somewhere besides the four most common choices (this set includes private and out-of-state colleges). Additionally, fewer quarters are matched for students who start at the state flagships, the University of Michigan and Michigan State. ${ }^{15}$ These patterns suggest academic aptitude may be related to matching in the data, a subject to which we return below. However, this correlation is not necessarily a threat to our identification, as the Promise is universal and without any merit requirements - indeed there is no significant difference in eligibility between all high school graduates and those who match.

Nonetheless, a more direct test of possible bias is whether the probability of matching is systematically correlated with Promise eligibility once the program is in effect. Therefore, and third, we implement a difference-in-difference specification similar to the one described in the next section, estimating the impact of Promise eligibility for post-Promise cohorts on the likelihood of matching for each calendar quarter since high school graduation. The point estimates (and 95 percent confidence intervals) for this set of regressions are shown in Figure 2. In no quarter is the difference-in-differences estimate statistically significant, nor are they jointly significant. There thus does not appear to be á priori evidence that the differential match rates

\footnotetext{
${ }^{15}$ As discussed later, students attending these selective institutions are more likely to leave the state at some point after they graduate.
} 
threaten valid estimation. However, we adopt additional approaches below to further probe this assertion.

\section{Estimation Strategy}

To identify impacts of the Kalamazoo Promise on workforce outcomes, we follow Bartik, Hershbein, and Lachowska (2020) in estimating difference-in-differences, comparing eligible and ineligible students, before and after the Promise began, holding constant any time-invariant pre-Promise differences between students who enrolled in KPS before or after ninth grade. More specifically, we estimate the following equation:

(1) $y_{i c s t}=\alpha+\delta_{1} \widetilde{E l i g}_{i c s t}+\delta_{2}(\text { After } \times \widetilde{\text { Elig }})_{i c s t}+\gamma_{c s}+\boldsymbol{x}_{i c s} \boldsymbol{\beta}+u_{i c s t}$,

where $i$ denotes the individual student, $c$ denotes the graduating cohort, $s$ denotes the high school, and $t$ denotes the time period in which we observe the individual. The outcome variable, described in more detail below, is denoted by $y$.

In the post-Promise period, Elig equals one if the student is observed as eligible according to Promise administrative records and zero otherwise; in the pre-Promise period, Elig equals one if the student is eligible based on historical enrollment in KPS and zero otherwise. After $\times \widetilde{\text { Elig }}$ is an interaction between Elig and After (a dummy that equals one if the student graduated after the Promise was in effect - the class of 2006 and later-and zero if before). The regression also includes graduation-year-by-high-school dummies, $\boldsymbol{\gamma}_{c s}$, encompassing years 2003 through 2013 and three high schools. The vector $\boldsymbol{x}$ contains fixed student-level characteristicssex, race and ethnicity, and eligibility for free or reduced-price lunch — and $u$ denotes student $i$ 's unobservable traits (the error term). The coefficient of greatest interest in Equation (1) is $\delta_{2}$ : the regression-adjusted difference in average outcomes between Promise-eligible and ineligible 
students, net of pre-Promise differences between students who enrolled before or after ninth grade. ${ }^{16}$

Given our quarterly UI data, we focus on the following outcomes: 1) binary employment status, defined variously to be at least two, three, and four quarters with positive earnings in a four-quarter period; 2) real average quarterly earnings within a four-quarter period ${ }^{17}$;3) the earnings distribution, whether real average quarterly earnings are above several sequential thresholds; and 4) motivated by the local economic development aspects discussed in the introduction, whether the individual is within certain concentric circle distance (using ZIP code centroids) from Kalamazoo's central business district.

For ease of interpretation, we operationalize the quarterly data into observations at the individual-year level. Here, years are since high school graduation, in which for an individual who graduated in year $t, \mathrm{Q} 3$ and Q4 of year $t+k-1$ and Q1 and Q2 of year $t+k$ constitute the $k$ th year since graduation. We further group our sample into three time horizons: 1-3 years since graduation, 4-6 years since graduation, and 7-10 years since graduation. To allow for flexible estimation, particularly in regard to the relationship of the controls to the outcome, we estimate equation (1) separately for each time horizon. (Conceptually and empirically, years 1-3 represent a time of postsecondary enrollment for most Promise students, years 4-6 represent a transition from college to the workforce, and years $7-10$ represent early career.) Thus, we have between three and four (potential) observations per individual for most outcomes, and we allow for arbitrary correlation by clustering standard errors at the individual level.

\footnotetext{
${ }^{16}$ We have experimented with including time-varying measures of the state unemployment rate and job growth as controls, but these do not affect estimates of $\delta_{2}$, as time-varying aggregate measures are implicitly captured by the cohort by high school fixed effects.

${ }^{17}$ We adjust for inflation to year 2018 dollars using the personal consumption expenditures deflator from the Bureau of Economic Analysis.
} 
The validity of our difference-in-differences strategy rests on two primary assumptions. The first is that outcomes were trending similarly for eligible and ineligible students before the Promise. That is, in a hypothetical world without the Promise, outcomes of eligible and ineligible students would have followed a common, parallel trend, conditional on observables. The second assumption is that no other change in KPS besides the Promise affected eligible and ineligible students' outcomes in a differential way. Although Bartik, Hershbein, and Lachowska (2020) thoroughly investigate these assumptions and find them quite plausible, the incomplete UI match rates add a wrinkle in that outcomes are not observed for every individual. Thus, there is potential for bias in our estimates. We attempt to address this potential bias (besides flexibly controlling for covariates) in several ways.

First, we create different cuts of the estimation samples as a form of sensitivity analysis. In some cases, we restrict the analytic sample to individuals with at least one matched quarter in a year to capture effects for people with some minimal presence in the Michigan (UI-covered) labor market that year. In others, particularly for the earnings outcomes, we follow existing literature (e.g., Scott-Clayton and Zafar 2019) and construct annual measures using only quarters with positive earnings. In addition to these ad hoc approaches, we also more systematically estimate a sequence of logit regressions to predict match rates for each calendar quarter elapsed since high school graduation as a function of high school demographic, academic, and neighborhood characteristics. Averaging these predicted rates across quarters for each person, we classify individuals in the top half of average predicted match rates as a "high-match-rate" sample. ${ }^{18}$ Interestingly, individuals with top academic credentials (high school GPAs and

\footnotetext{
${ }^{18}$ These predictions are available upon request. Regressors for the prediction included the variables shown in Table 3, as well as standardized test scores and characteristics of the Census Tract of the individual's last known KPS address. These latter characteristics include the share of adult residents with a high school diploma, the share
} 
standardized test scores) are predicted to be less likely to match in the data, and this gap increases with time horizon. Because these individuals also have high potential earnings, the pattern is consistent with them being more likely to leave the state (and the scope of the data). However, low predicted match rates were also found among the academically weakest students in our sample, implying both positive and negative selection. In fact, the individuals most likely to match regularly were students of middling academic preparation who attended either the local two- or four-year college.

Analyzing these samples separately yields a conceptually different average treatment effect on the treated than analyzing the full sample. Based on the findings in Bartik, Hershbein, and Lachowksa (2020), the high-match-rate sample constitutes individuals who were more likely to be on the margin of completing a degree because of the Promise. To the extent that degree attainment is a principal mechanism of improved labor market outcomes, which seems plausible, the high-match-rate sample may provide estimates closer to marginal treatment effects on the treated that are of particular policy interest.

Second, and perhaps more pertinent to heterogeneity, we also estimate impacts on subgroups defined by gender, race/ethnicity, and eligibility for free and reduced-price lunch. These characteristics are slightly correlated with match rates (Table 3), but in conjunction with the estimated heterogeneity of Promise impacts on degree attainment (Bartik, Hershbein, and Lachowksa 2020), differential workforce impacts are potentially informative when it comes to probing issues of nonrepresentativeness, as well.

Third, we supplement the quantitative analysis of UI data with qualitative telephone interviews of individuals we were able to identify as having left Michigan (and thus the UI data)

with at least a bachelor's degree, the poverty rate, the share of occupied homes that are rented, and the share of family households that are led by single parents. 
through Promise contact information and a snowball sample approach. These conversations focused on motivations for working within or outside the state, as well as the nature of employment and its relation to educational attainment. These interviews, described more thoroughly in the discussion section, provide contextual information on students not captured in the earnings analysis and thus a more holistic look at the overall workforce impact of the Kalamazoo Promise.

\section{RESULTS}

\section{A. Employment}

One way to capture employment would be to check for any positive earnings in a given year - that is, at least one quarter with positive employment. However, since an individual who does not work in a given quarter will not have a UI record that quarter - and thus not match that quarter - this definition is essentially identical to whether an individual has a match in the data that year. Because Figure 2 already indicated that the Kalamazoo Promise was not associated with overall match rates, an outcome defined this way is not particularly interesting.

Therefore, we capture the effect of the Promise on employment as measured by positive earnings in (successively) two, three, and all four quarters in a year. This measure intrinsically also captures the intensive margin, or intensity, of employment. The three panels of Table 4 show estimates of $\delta_{2}$ for each of these employment intensities.

In general, we find minimal impacts on any of these employment intensities, at any horizon from immediately after high school to 7-10 years after. The first three columns show effects at these time horizons for the full, rectangularized sample, in which unmatched personquarters are treated as implicit zeroes. The point estimates, although all positive, are uniformly 
small, below 2 percentage points. Moreover, they are not especially precise. For example, in column 3 of panel C, we cannot rule out an all-quarter employment increase at the 7-10-year horizon of up to about 8 percentage points ( 26 percent of the base) or a decrease of up to about 6 percentage points ( 20 percent). This relative imprecision may in part be due to inclusion of unmatched person-quarters; focusing on samples with greater match rates—and thus demonstrated labor force presence in Michigan — could yield estimates more in line with an intensive margin of employment interpretation. Columns 4 through 6 thus focus on the sample with high predicted match rates (as described on page 16), but estimates and inference are both similar to the full sample. ${ }^{19}$ Because so many of these estimates cluster around 0 , even though somewhat noisily, we infer that strong Promise impacts on employment—at least in Michiganare unlikely.

\section{B. Earnings Levels}

Table 5 shows the impact of the Promise on real average quarterly earnings (in levels). Panel A again uses the full rectangularized sample that treats unmatched quarters as implicit zeros (before averaging across the year), while panel B restricts the sample to quarters with positive earnings. The estimates in panel A thus capture changes in both the extensive and intensive margins, while those in panel B capture changes in the latter. In practice, the distinction turns out not to matter much. Across the three time horizons in columns 1 through 3, the patterns are similar for both panels: small negative point estimates in the two earlier horizons (when individuals were probably still enrolled in school; Bartik, Hershbein, and Lachowska 2020), and

${ }^{19}$ As another robustness check, in Appendix Table A3, we condition the sample on an individual having at least one quarter of positive earnings in a given year (signaling minimal labor force attachment in Michigan). We find slightly negative estimates at 4-6 years, when many individuals are still enrolled in college, and slightly positive estimates at $7-10$ years, but none is statistically significant. 
a somewhat larger, but still statistically insignificant, positive estimate in the later horizon. The estimate of \$489 in column 3 of panel A is a substantively large 20 percent of the mean earnings level of $\$ 2,441$ (which includes many zeros), although the t-statistic is only 1.55 . The estimate in panel $\mathrm{B}$ of $\$ 389$ is off a base of $\$ 6,354$, or a modest 6 percent, when only positive-earnings quarters are included, but the confidence intervals are wide enough that proportional impacts between -10 percent and $(+) 22$ percent cannot be rejected. The picture is unchanged in the highmatch sample of columns 4 through 6 , as well as in the sample that includes only individuals with at least one matched quarter per year (Appendix Table A4). While these results do not preclude the possibility of the Kalamazoo Promise raising individuals' earnings by their mid-tolate 20s, they do not represent compelling evidence for such a boost either.

\section{Earnings Distribution}

The effects on average earnings levels shown in Table 5 may mask important impacts at other parts of the earnings distribution, especially since the distribution is highly skewed, with a long right tail. The Promise, for example, could meaningfully raise earnings in the bottom half of the distribution while not significantly affecting the mean. There are many ways to investigate this possibility, including several variants of quantile regression, but many of these methods require several additional assumptions, can be difficult to interpret, or both (Callaway and Li 2019). Instead, we adopt a simpler approach of discretizing earnings into $\$ 500$ bins, ranging between $\$ 2,000$ and $\$ 12,000$, and defining a sequence of binary indicators for whether an individual's real average quarterly earnings in a year exceed the floor of each bin. ${ }^{20}$ This approach allows us to use equation (1) in the standard way, as a linear probability model, with a

\footnotetext{
${ }^{20}$ Michigan's minimum wage ranged from $\$ 5.15$ in 2006 (the federal minimum) to $\$ 9.45$ in 2019; adjusted to year 2018 dollars, the range is $\$ 6.25$ to $\$ 9.31$. The $\$ 2000$ threshold thus corresponds to between 215 and 320 hours of minimum wage work a quarter, or roughly 16 to 25 hours per week.
} 
straightforward interpretation of $\delta_{2}$ representing the change in the likelihood that a Promiseeligible individual has earnings in that bin or a higher one.

We illustrate these estimates graphically in Figure 3. Because we don't have a balanced panel for the pre-Promise cohorts, we focus on the 4-6- and 7-10-year horizons. Panels A and B show the distributional effects for these respective horizons, using the full sample and treating unmatched quarters as implicit zeros. Panels $\mathrm{C}$ and $\mathrm{D}$ show effects based on the sample that includes only quarters with positive earnings. ${ }^{21}$

Panel A shows near-zero effects throughout the earnings distribution for KPS graduates when they are approximately 22-24 years old. But many individuals are still enrolled in college at this horizon. Thus, panel B focuses on the horizon when most graduates are 25-28 years old. Here, we see relatively sizable increases, which steadily grow until approximately the midpoint of the earnings range shown. Put differently, there are minimal impacts at the bottom threshold of $\$ 2,000$ per quarter (which, because of the inclusion of implicit zeros, only about one-third of this sample exceeds). But there are impacts of between 4 and 6 percentage points at thresholds ranging from $\$ 4,000$ to $\$ 10,000$ per quarter, and some of these impacts - particularly in the upper two-thirds of the range- are statistically significant at the 0.05 level. Given the low mean shares exceeding thresholds in this range (e.g., the mean is 13.7 percent for the $\$ 7,000$ threshold), the proportional impacts are considerable: the increases are between 40 and 60 percent in the fraction of Promise-eligible individuals with earnings at annualized rates of up to about $\$ 40,000 .{ }^{22}$ Nonetheless, in absolute terms, the estimates are consistent with only about 25 additional graduates having annualized earnings above that threshold.

\footnotetext{
${ }^{21}$ Appendix Figure A1 repeats Figure 3 but with the high-match-rate sample.

${ }^{22}$ A lack of earnings impacts at the mean (Table 5) may be due to the well-known large right skew of earnings.
} 
These impacts implicitly include effects of both employment and earnings. By restricting the estimation sample to quarters with positive earnings in panels $\mathrm{C}$ and $\mathrm{D}$, we focus on the extensive margin of earnings impacts. Panel C shows negative impacts in the $2-4$ percentage point range throughout the distribution, but none is statistically significant, and as noted above, the timing is early. For the $7-10$-year horizon shown in panel $\mathrm{D}$, the general pattern is roughly consistent with that in panel B. The Promise raises by about 4-5 percentage points the likelihood that individuals surpass quarterly earnings of $\$ 4,000$ to $\$ 9,500$. However, due to the smaller sample from the conditional restriction, none of these estimates is statistically significant (some just miss significance at the 0.10 level). In proportional terms, given the much higher means from excluding implicit zeros, the impacts are smaller than in panel $\mathrm{B}$ - on the order of a 7 percent increase. ${ }^{23}$

These distributional impacts are somewhat more salutary than the lack of earnings effects at the mean, but they are also relatively modest and not especially precisely estimated. The Kalamazoo Promise may have raised earnings in the middle part of the distribution, but the evidence is not as compelling as its effect on degree attainment (Bartik, Hershbein, and Lachowska 2020).

\section{Location Choice}

As noted above, place-based scholarships differ from traditional merit- and need-based scholarships in that they often contain an explicit workforce and economic development motivation beyond greater human capital attainment. That is, the goal isn't just boosting degrees but increasing the share of high school graduates with college degrees who choose to work and

${ }^{23}$ Estimates for the high-match-rate sample (Appendix Figure A1) are generally similar to those shown in Figure 3, although, consistent with the smaller sample, the estimates are noisier. 
live in the local community. Thus, it is of policy interest to understand how the Kalamazoo Promise affected KPS graduates' location choices. We use residential ZIP code information in the UI data and calculate distances between the centroids of the residential ZIP code and that of Kalamazoo's central business district. ${ }^{24}$ We discretize these distances into the following categories: within five miles, within 10 miles, within 20 miles, and within 50 miles. The lowest threshold roughly captures the immediate KPS area, while the highest threshold is near a maximum plausible commuting distance. We are able to observe residential ZIP codes outside Michigan if the individual works for a company covered by Michigan UI (i.e., a commuter into the state), but not within-Michigan residential ZIP codes if the individual does not work for a company covered by Michigan UI. The latter case includes individuals who may be living in the state but not working. We annualize the quarterly ZIP code reports by taking the (first) mode across quarters, so even a single-quarter match within a year will permit a valid observation.

Table 6 shows Promise impacts on the probability of an individual living within the above-specified distances from the city's central business district. Unlike those for employment and earnings, these estimates show stronger evidence of a Promise effect. In the first three columns of panel A, the Promise appears to raise the probability of living within five miles of downtown Kalamazoo by 9-13 percentage points (15-23 percent), although only the estimate at the 4-6-year horizon is marginally statistically significant, and even that finding is not robust to the high-match-rate sample (column 5). The estimates are stronger, however, in panels B and C, which display impacts at the 10- and 20-mile thresholds, respectively. Across both the full and high-match-rate samples, Promise-eligible individuals are between 9 and 17 percentage points

${ }^{24}$ Technically, we use centroids from ZIP Code Tabulation Areas (ZCTAs), available from the Census Bureau's Gazetteer files. ZCTAs matched ZIPs exactly in nearly all cases. We construct distances using the latitudelongitude coordinates in the Gazetteer files and the Stata user-written program, -geodist- (Picard 2010). 
(11 and 22 percent) more likely to live within 10 miles of Kalamazoo 4-10 years after high school, and between 11 and 19 percentage points (14 and 21 percent) more likely to live within 20 miles. These results are almost all statistically significant at conventional thresholds, sometimes at better than the 0.01 level. There are also positive effects at the 50-mile threshold, arguably near an upper commuting limit. As shown in Appendix Table A5, all of these results are also robust to a sample that includes only individuals with at least one matched quarter per year.

These findings indicate that the Promise has been successful in retaining more (Promiseeligible) KPS graduates in the area, especially when the area loosely matches a labor market. ${ }^{25}$ Nonetheless, the earlier results suggest that, although more individuals are staying local, they aren't more likely to be employed or earning higher wages, and this may limit the program's potential as a tool for local economic development.

\section{E. Heterogeneity}

Finally, we examine effects separately by race, sex, and eligibility for free and reducedprice lunch, our proxy for family income status. Table 7 shows longer-term Promise effects (710 years after high school) by subgroup for four outcomes: minimum labor force attachment, average quarterly earnings, whether quarterly earnings are above a threshold of $\$ 4,000$, and whether the former student lived within 10 miles of Kalamazoo's central business district. These results are broadly consistent with our overall findings and are of the expected sign in almost all cases. However, our subgroup estimates are less precise than those of the full samples, and so meaningful inference or comparisons between groups is difficult.

\footnotetext{
${ }^{25}$ Grand Rapids, for example, is a large, relatively fast-growing metro area that is about 50 miles north of Kalamazoo. Stronger results at the 10- and 20-mile horizons suggest less movement by the Promise-eligible to other nearby metros.
} 
The first row of Table 7 shows positive point estimates for labor-force attachment (defined as having four quarters of positive earnings in a 12-month period) for all subgroups with the exception of racial minorities, who essentially saw no change (a -0.3 percent reduction from their mean). As with our estimates of labor force attachment on the full sample, no estimate among the subgroups is statistically significant, nor are estimates meaningfully different between groups. Due to imprecision, we generally cannot rule out changes of up to 10 percentage points on either side of the point estimate, which can represent up to 30 percent of the control mean. Unfortunately, the measure of labor force attachment is simply too noisy to draw conclusions about Promise impacts on subgroups.

Estimates on average quarterly earnings, in the second row, are universally positive across groups and somewhat more precise than those for labor force attachment. Although the relative impacts are of meaningful size —increases of 28 percent for women $(=470.2 / 1,702), 18$ percent for men, 36 percent for whites, 14 percent for minorities, and 22 percent for low-income people — only the result for whites is marginally significant. Likewise, the Promise's impact for earning above the threshold of $\$ 4,000$ per quarter is also positive for each subgroup, with the largest effect for women, who experienced a 33 percent increase in the likelihood of earning above the threshold. Despite these sizable estimates, confidence intervals are wide, and we cannot rule out that no meaningful differences exist between groups for these outcomes, or that the true differences are in fact much larger.

The last row of Table 7 examines effects on the likelihood of each group living within 10 miles from the city's central business district. Estimates for this outcome diverge more than for the earlier labor market outcomes, with men 20 percentage points (33 percent), whites 23 percentage points ( 31 percent), and those who had been low-income students 16 percentage 
points (18 percent) more likely to live closer to Kalamazoo. All three of these estimates are statistically significant. Women, racial minorities, and those who had been higher-income students were also more likely to live nearby in the post-Promise era, but the effects were weaker and not statistically significant. However, again because of imprecision, we cannot reject that effects across the groups are the same.

\section{DISCUSSION}

As discussed previously, state UI wage records do not fully capture the impact of the Kalamazoo Promise on workforce outcomes, particularly around the question of where students are employed after graduation. Because the UI data do not contain information on students who leave the state, relying wholly on them for inference could skew our knowledge about the kinds of jobs Kalamazoo Promise students have taken, and the data provide no information on factors leading to the decision to leave the state.

Thus, we have also begun conducting a supplemental study (still underway) to understand the employment experiences of KPS graduates employed outside Michigan. More specifically, we targeted KPS graduates from the classes of 2006-2014 from the following categories for a semi-structured telephone interview:

- Those who used the Kalamazoo Promise at eligible in-state institutions who subsequently secured employment outside of Michigan.

- Those who attended college or university outside the state (without the Kalamazoo Promise) and are currently (or were previously) employed out of state.

- Those who did not attend or complete college and moved out of state.

We initially began with graduates known to have met one of these criteria by the authors or Promise staff, then expanded the sample using the "snowball survey" technique by asking 
participants to assist in identifying other potential subjects. ${ }^{26}$ To date, 36 (of a planned 50) interviews have been completed. Of interest are the conditions leading respondents to take employment out of state; the nature of their employment, including wages; and whether the respondents have current plans to return to Michigan or the local community.

Most of the individuals interviewed attended either the local four-year college, Western Michigan University, or one of the state flagships, Michigan State University and University of Michigan (Ann Arbor campus); a few also attended college out of state and thus did not use the Promise. Based on our estimations of the match rate, described above, this college distribution is aligned with individuals who were less likely to be found in the UI data.

Interviewed students are geographically dispersed, spanning 24 cities in 16 states, plus one person residing outside the United States. Not all traveled far: six individuals were living and working in Chicago, about 150 miles from Kalamazoo. Most of the interviewed students were faring quite well economically: more than one-third reported annual earnings over $\$ 75,000$, and more than one-fifth reported earning over $\$ 100,000$. These earnings levels are much higher than found in the state UI data (where less than 2 percent had annualized earnings over $\$ 75,000$ ), strongly suggesting that the interview sample — and quite likely most of the population of out-ofstate KPS graduates - is positively selected on earnings capacity. ${ }^{27}$

Indeed, just over half of the respondents cited an employment offer and a more professionally advantageous and/or lucrative nature of work than was available within Michigan as reasons for moving out of state. Others expressed a preference for leaving their home state for

\footnotetext{
${ }^{26}$ Although the interview questions are not particularly sensitive (the instrument appears in the Appendix), we took steps to preserve subjects' privacy, and only one of the authors - the interviewer-could match names to responses.

${ }^{27}$ Given the strong correlation between academic aptitude and earnings capacity, this also suggests that the out-of-state KPS graduate population may not have been marginal in terms of the Promise causally increasing their likelihood of degree attainment. Put differently, the out-of-state residents are not the population of individuals for whom we would expect the largest Promise effect on earnings.
} 
personal development. All of them, however, held internships in fields related to their jobs for at least one semester or summer while in college. These internships were also largely, but not entirely, out of state. In addition to finding jobs through internships, many interviewees reported obtaining employment offers through university career offices, career fair networking, and internet job boards. Business and engineering graduates, who tend to have high earnings, were especially likely to have secured employment through events or services offered through their department's career office.

These qualitative findings indicate that the availability of local (or at least within-state) jobs may play an important role in retaining graduates of a place-based college scholarshipespecially the more successful ones. In conjunction with the analysis of the UI data, these patterns suggest that place-based scholarships, even when they significantly boost degree attainment, need not lead to improved labor market outcomes for affected students or to successful graduates staying in the community and contributing to economic development. The strength of the local job market may be an important mediator. The Kalamazoo metro area had about as many jobs in 2018 as it did in 2000, whereas the Knoxville metro area had seen its job total grow by 20 percent over the same horizon. ${ }^{28}$ Moreover, growth in professional \& business services and education \& health services - the sectors in which the largest shares of recent college graduates work ${ }^{29}$ — each grew by more than 50 percent in Knoxville, but only by about 20 percent and 40 percent, respectively in Kalamazoo. The patterns are similar if the comparisons are between the two states rather than the two metro areas. Thus, the positive

\footnotetext{
${ }^{28}$ Employment changes are calculated from the U.S. Bureau of Labor Statistics State and Metro Area Employment series.

${ }^{29}$ Based on the six states reporting in the U.S. Census Bureau's Post-Secondary Employment Outcomes program, a cooperative effort between select higher education institution systems that allow education records of their graduates to be merged to the Census Bureau's Longitudinal Employer-Household Dynamics, an integrated panel of all states' UI data. The top industries of employment are remarkably consistent across states and colleges.
} 
employment impacts of the Knox Achieves program found by Carruthers, Fox, and Jepsen (2020) could be related to Knoxville's faster growing labor market for college graduates. This hypothesis warrants future research, especially if place-based scholarships are intended to revitalize economic areas.

In the near future, we hope to expand our interview sample to include KPS graduates who pursued associate degrees, certificates, and other forms of job training and are currently employed outside of Michigan. We also aim to add context for differences by race and family income background.

\section{CONCLUSION}

In this paper, we have analyzed workforce outcomes from the Kalamazoo Promise, one of the earliest and most generous place-based college scholarships, a model that has expanded to hundreds of programs nationwide. Despite the large increases in educational attainment the Promise induced (Bartik, Hershbein, and Lachowska 2020), we find that these educational gains have not translated into clear and convincing gains in employment and earnings. Indeed, we find almost no evidence of employment increases at the extensive or intensive margins and only weak evidence of earnings gain at the mean. Although earnings increases in the middle of the distribution receive more empirical support, they are not particularly strong, either.

Given that Bartik, Hershbein, and Lachowska (2020) find degree attainment increases (at the six-year post-high school horizon) of 10-12 percentage points, two-thirds of which are from bachelor's degrees, what earnings impact might we expect, given previous research? The causal impact of a bachelor's degree on earnings in one's late 20s has been estimated to be on the order of 68 percent, and that of an associate degree about 29 percent, both relative to only a high 
school diploma (Hershbein, Kearney, and Pardue 2020a, 2020b; Zimmerman 2014). Assuming no other earning impacts other than through these degree attainment channels, a back of the envelope calculation suggests an expected average earnings increase of $0.075 \times 0.68+0.035 \times 0.29$ $=0.061$, or 6.1 percent. This is a lower bound, as college enrollment and credit attainment not leading to a degree also have some labor market returns (Hershbein, Kearney, and Pardue 2020b). This figure is pretty close to the modal point estimate for the longer time horizon in Table 5, so it is quite possible that we simply lack statistical power to detect reasonable earnings impacts. Nevertheless, our point estimates for earnings effects among a sample predicted to have a high match rate in the UI data - and one for which Promise degree completion impacts are especially likely to be concentrated - are smaller, when we would expect them to be larger.

A conservative inference would thus imply that there is not compelling evidence that the Kalamazoo Promise increased earnings of Promise-eligible high school graduates, even if this outcome cannot be rejected. What might explain this lack of impact, especially when emerging evidence suggests more salutary impacts from the predecessor to the community-college scholarship Tennessee Promise (Carruthers, Fox, and Jepsen 2020)? Although more research is needed, we suspect that local labor markets might be important. The Kalamazoo area, and the state of Michigan more generally, has not seen the recent job or population growth of Knoxville, Tennessee. If local job opportunities are lacking, it is possible that place-based college scholarships could very well lead to increased educational attainment but not improved employment and earnings. As more states adopt explicit education goals to reach a certain share of their working-age population with post-secondary education credentials, our results serve as a cautionary reminder that greater educational attainment by itself may not be sufficient to lead to 
better workforce outcomes, and that additional measures to promote job development may be necessary. 


\section{References}

Angrist, Joshua, David Autor, and Amanda Pallais. 2020. "Marginal Effects of Merit Aid for Low-Income Students.” NBER Working Paper No. 27834. Cambridge, MA: National Bureau of Economic Research.

Bartik, Timothy J., Randall W. Eberts, and Wei-Jang Huang. 2010. “The Kalamazoo Promise and Enrollment and Achievement Trends in Kalamazoo Public Schools." Upjohn Institute Conference Paper No. 15. Kalamazoo, MI: W.E. Upjohn Institute for Employment Research.

Bartik, Timothy J., Brad J. Hershbein, and Marta Lachowska. 2016. "The Merits of Universal Scholarships: Benefit-Cost Evidence from the Kalamazoo Promise." Journal of BenefitCost Analysis 7(3): 400-433. DOI: https://doi.org/10.1017/bca.2016.22.

Bartik, Timothy J., Brad J. Hershbein, and Marta Lachowska. 2020. "The Effects of the Kalamazoo Promise Scholarship on College Enrollment and Completion." Journal of Human Resources 56(1): 269-310. DOI: https://doi.org/10.3368/jhr.56.1.0416-7824R4.

Bettinger, Eric, Oded Gurantz, Laura Kawano, Bruce Sacerdote, and Michael Stevens. 2019. "The Long-Run Impacts of Financial Aid: Evidence from California's Cal Grant." American Economic Journal: Economic Policy 11(1): 64-94. DOI: https://doi.org/10.1257/pol.20170466

Black, Sandra E., Jeffrey T. Denning, Lisa J. Dettling, Sarena Goodman, and Lesley J. Turner. 2020. "Taking It to the Limit: Effects of Increased Student Loan Availability on Attainment, Earnings, and Financial Well-Being." NBER Working Paper No. 27658. Cambridge, MA: National Bureau of Economic Research.

Callaway, Brantly, and Tong Li. 2019. "Quantile Treatment Effects in Difference in Differences Models with Panel Data." Quantitative Economics 10: 1579-1618.

Carruthers, Celeste K. and William F. Fox. 2016. "Aid for All: College Coaching, Financial Aid, and Post-Secondary Persistence in Tennessee." Economics of Education Review 51: 97 112. https://doi.org/10.1016/j.econedurev.2015.06.001

Carruthers, Celeste K., William F. Fox, and Christopher Jepsen. 2020. "Promise Kept? Free Community College, Attainment, and Earnings in Tennessee." University of Tennessee working paper.

Chakrabarti, Rajashri, Nicole Gorton, and Michael F. Lovenheim. 2020. "State Investment in Higher Education: Effects on Human Capital Formation, Student Debt, and Long-Term Financial Outcomes of Students." Federal Reserve Bank of New York Staff Reports No. 941. 
Chakrabarti, Rajashri, William Nober, and Wilbert van der Klaaw. 2020. "Do College Tuition Subsidies Boost Spending and Reduce Debt? Impacts by Income and Race." Federal Reserve Bank of New York Liberty Street Economics. July 8.

Deming, David, and Susan M. Dynarski. 2010. "College Aid." In Targeting Investments in Children: Fighting Poverty When Resources Are Limited, Phillip B. Levine and David J. Zimmerman, eds. Chicago: National Bureau of Economic Research and University of Chicago Press. 283-302.

Denning, Jeffrey T., Benjamin M. Marx, and Lesley J. Turner. 2019. "ProPelled: The Effects of Grants on Graduation, Earnings, and Welfare." American Economic Journal: Applied Economics 11(3): 193-224. https://doi.org/10.1257/app.20180100.

Forsythe, Eliza. 2019. “Why Don't Firms Hire Young Workers During Recessions?” University of Illinois mimeo.

Hendren, Nathaniel, and Ben Sprung-Keyser. 2020. "A Unified Welfare Analysis of Government Policies.” Quarterly Journal of Economics 135(3): 1209-1318.

Hershbein, Brad. 2013. "A Second Look at Enrollment Changes after the Kalamazoo Promise." Upjohn Institute Working Paper 13-200. Kalamazoo, MI: W.E. Upjohn Institute for Employment Research.

Hershbein, Brad, Melissa S. Kearney, and Luke W. Pardue. 2020a. "College Attainment, Income Inequality, and Economic Security: A Simulation Exercise." AEA Papers and Proceedings 2020: $110352-355$.

Hershbein, Brad, Melissa S. Kearney, and Luke W. Pardue. 2020b. "College Attainment, Income Inequality, and Economic Security: A Simulation Exercise." NBER Working Paper \#26747.

MI School Data. 2019. Retrieved from https://www.mischooldata.org/Default3.aspx.

Miller-Adams, Michelle. 2015. Promise Nation: Transforming Communities Through PlaceBased Scholarships. Kalamazoo, MI: W.E. Upjohn Institute for Employment Research. DOI: https://doi.org/10.17848/978088099506.

Miller-Adams, Michelle, Brad Hershbein, Bridget Timmeney, and Isabel McMullen. 2020. Promise Programs Database. Kalamazoo, MI: W.E. Upjohn Institute for Employment Research.

Page, Lindsay, C. and Jennifer Iriti. 2016. "On Undermatch and College Cost: A Case Study of the Pittsburgh Promise." In Matching Students to Opportunity: Expanding College Choice, Access, and Quality, Andrew P. Kelly, Jessica S. Howell, and Carolyn SatinBajaj, eds. Cambridge, MA: Harvard Education Press. 
Page, Lindsay, C. and Judith Scott-Clayton. 2016. "Improving College Access in the United States: Barriers and Policy Responses." Economics of Education Review 51: 4-22. https://doi.org/10.1016/j.econedurev.2016.02.009.

Picard, Robert. 2010. "GEODIST: Stata module to Compute Geodetic Distances." Statistical Software Components, Boston College Department of Economics.

Scott-Clayton, Judith, and Basit Zafar. 2019. "Financial Aid, Debt Management, and Socioeconomic Outcomes: Post-College Effects of Merit-Based Aid" Journal of Public Economics 170: 68-82. DOI: https://doi.org/10.1016/j.jpubeco.2019.01.006.

Swanson, Elise, and Gary Ritter. 2020. "Start to Finish: Examining the Impact of the El Dorado Promise on Postsecondary Outcomes." Journal of Student Financial Aid 49(3): 1-30.

W.E. Upjohn Institute for Employment Research. 2021. Kalamazoo Promise: Data Collection. Kalamazoo, MI: W.E. Upjohn Institute for Employment Research.

Zimmerman, Seth. 2014. "The Returns to College Admission for Academically Marginal Students." Journal of Labor Economics 32(4) 711-754. 


\section{Figure 1 UI Match Rates by Cohort and Quarters since High School Graduation}

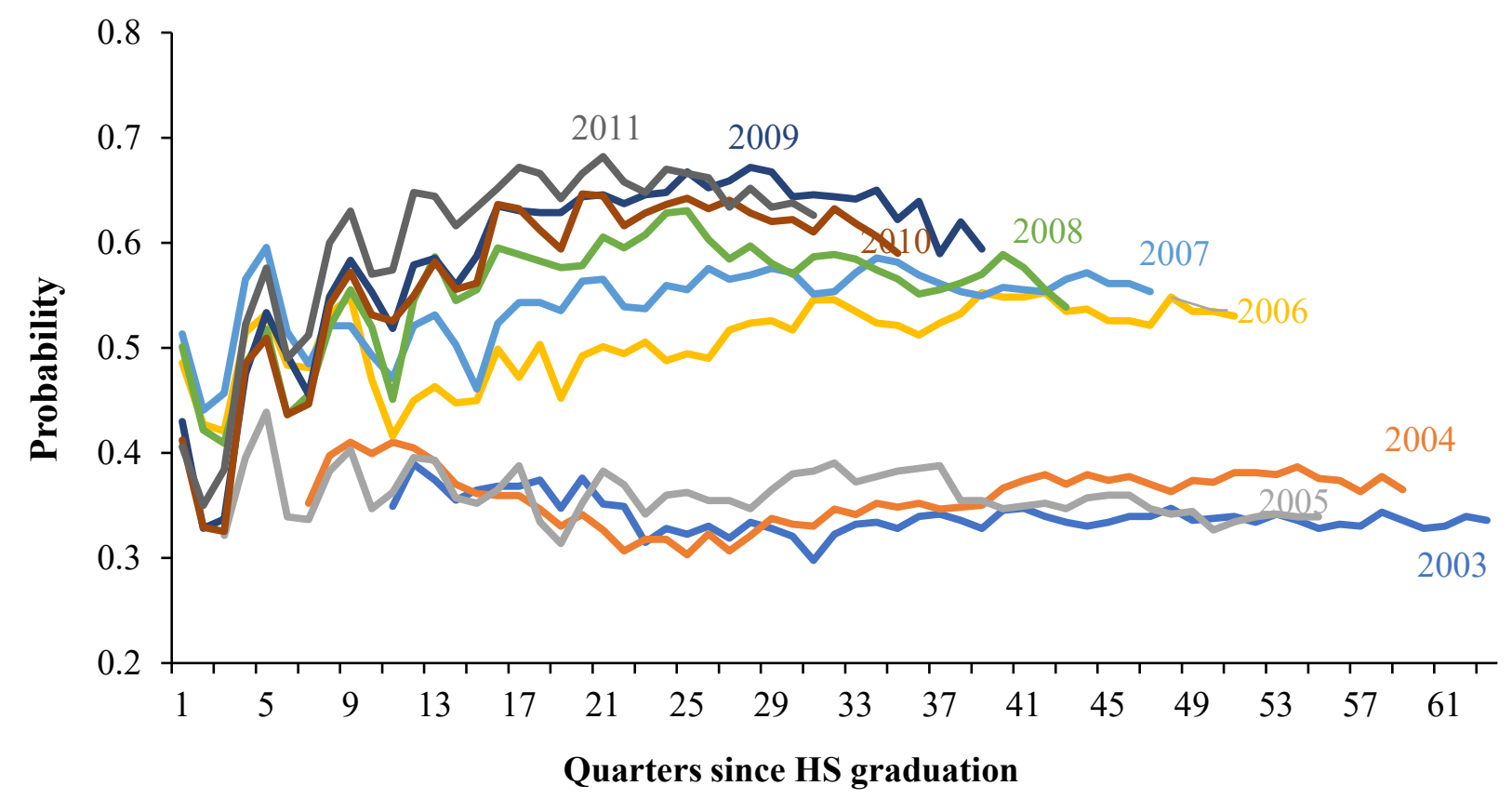

NOTE: Graduating totals by class are shown in Table 1. The series show, for each graduating KPS cohort, the average match rate by calendar quarter elapsed since high school graduation.

SOURCE: Authors' calculations from KPS and Michigan UI administrative data. 


\section{Figure 2 Quarterly UI Match Rates are Uncorrelated with Promise Eligibility}

\subsection{5}

0.20

0.15

0.10

0.05

0.00

$-0.05$

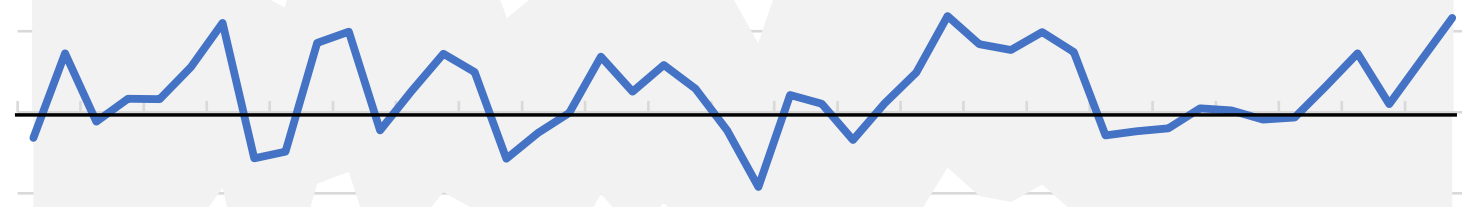

$-0.10$

$-0.15$

$-0.20$

$-0.25$

3

$7 \quad 11$

15

\section{$\begin{array}{lllll}19 & 23 & 27 & 31 & 35\end{array}$ \\ Quarters since HS graduation}

NOTE: Specification is as in equation (1) in the text, where the dependent variable equals 1 if an individual matches in the UI data in a given calendar quarter, and 0 if not. Regressors include the interaction of Promise eligibility with an indicator for being in a Promise cohort (the estimated coefficients of which are shown), cohort indicators, and indicators for sex, race/ethnicity, high school, and free/reduced-price lunch status. Ninety-five percent confidence intervals (shaded areas) are based on standard errors robust to heteroskedasticity.

SOURCE: Authors' calculations from KPS and Michigan UI administrative data. 


\section{Figure 3 Promise Effects on Earnings Distribution}

A. 4-6 years post-high school graduation

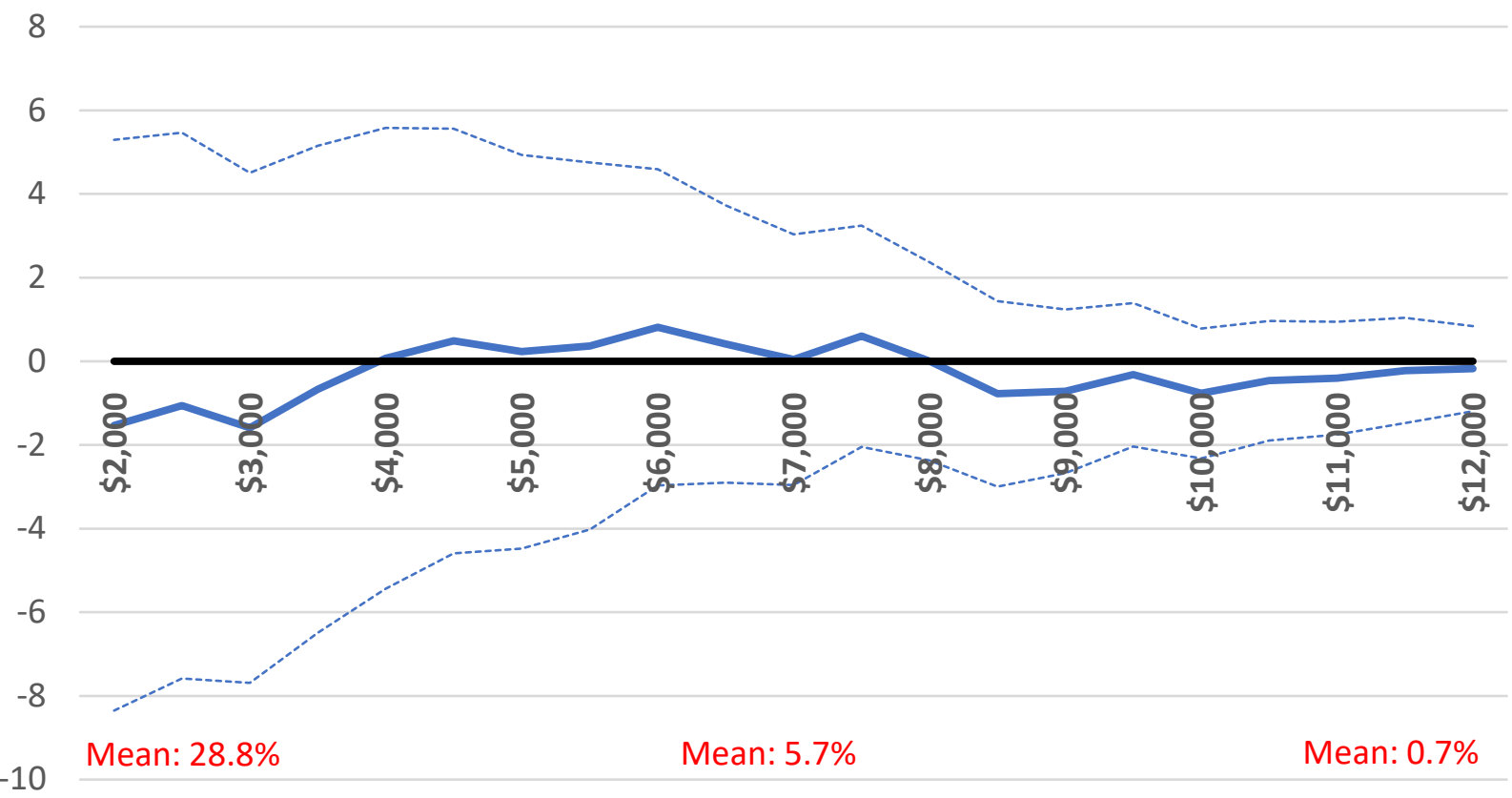

\section{B. 7-10 years post-high school graduation}

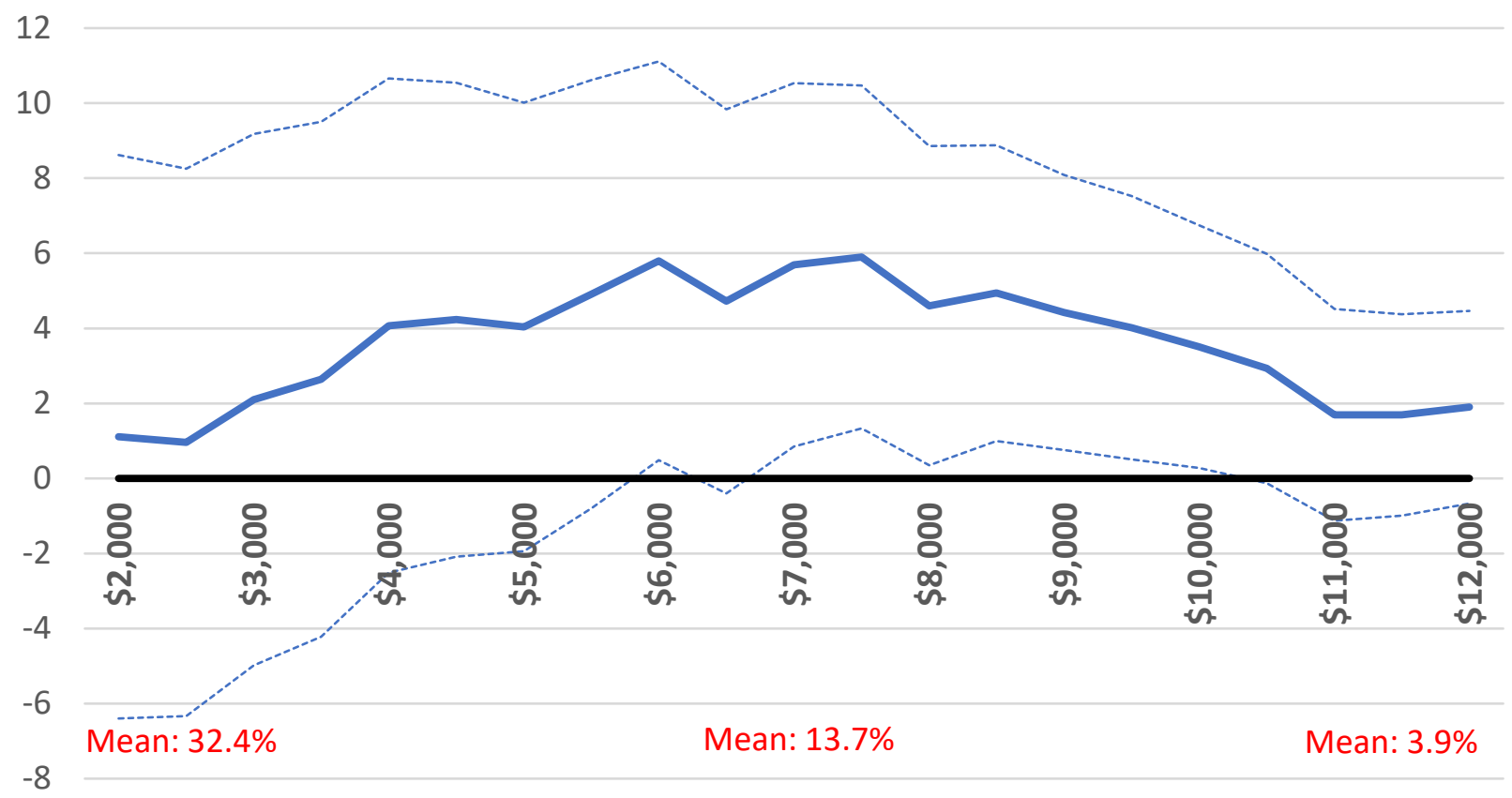




\section{4-6 years post-high school graduation: Only matched person-quarters sample}

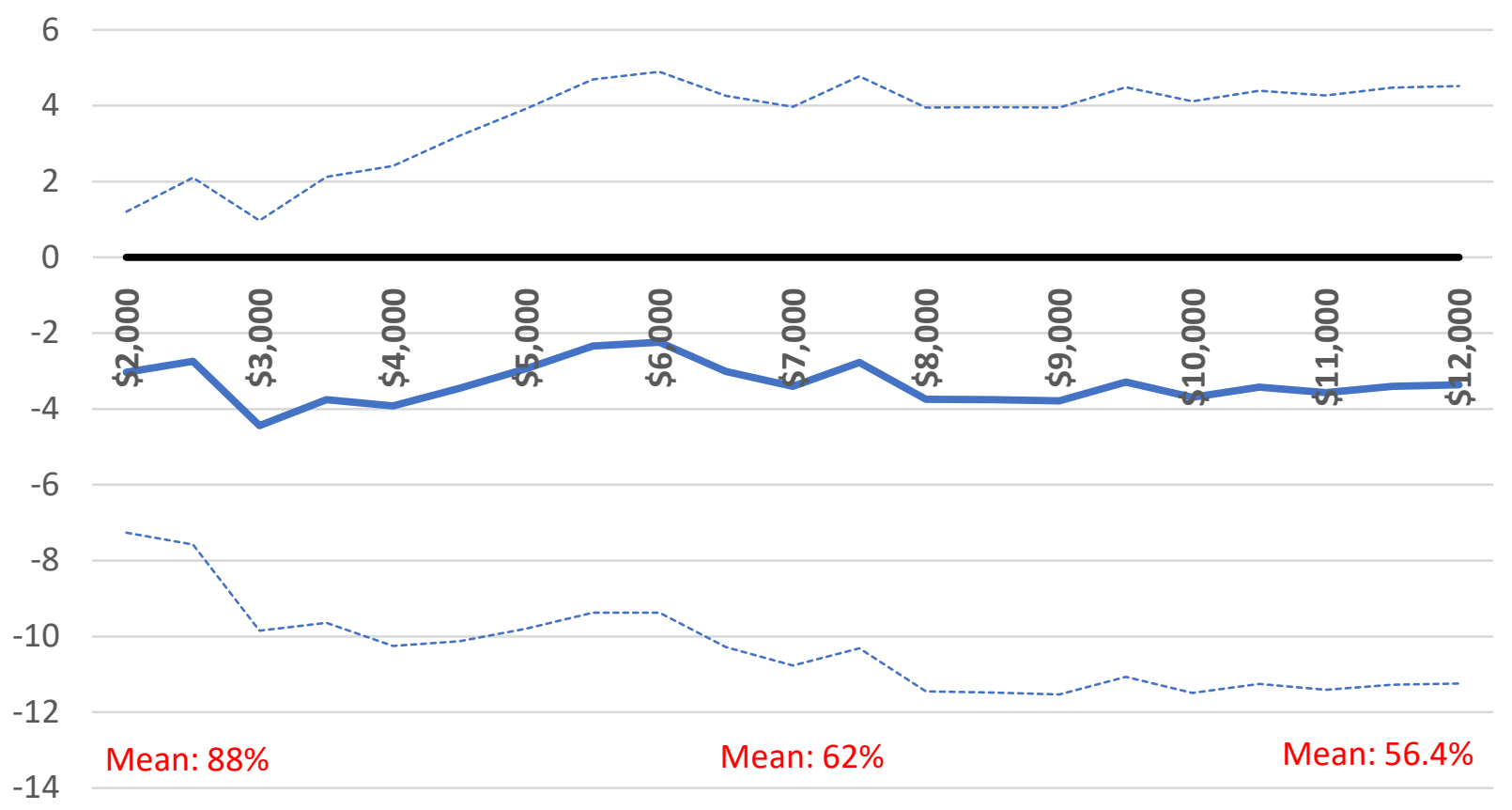

D. 7-10 years post-high school graduation: Only matched person-quarters sample

15

10

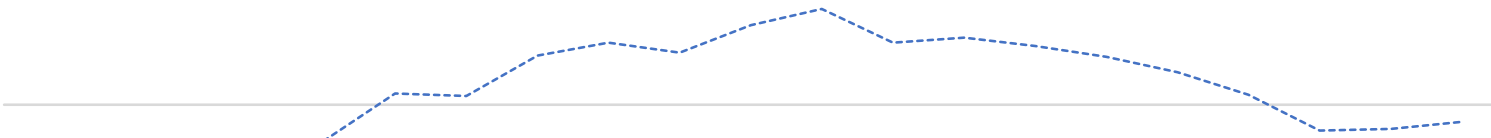

5
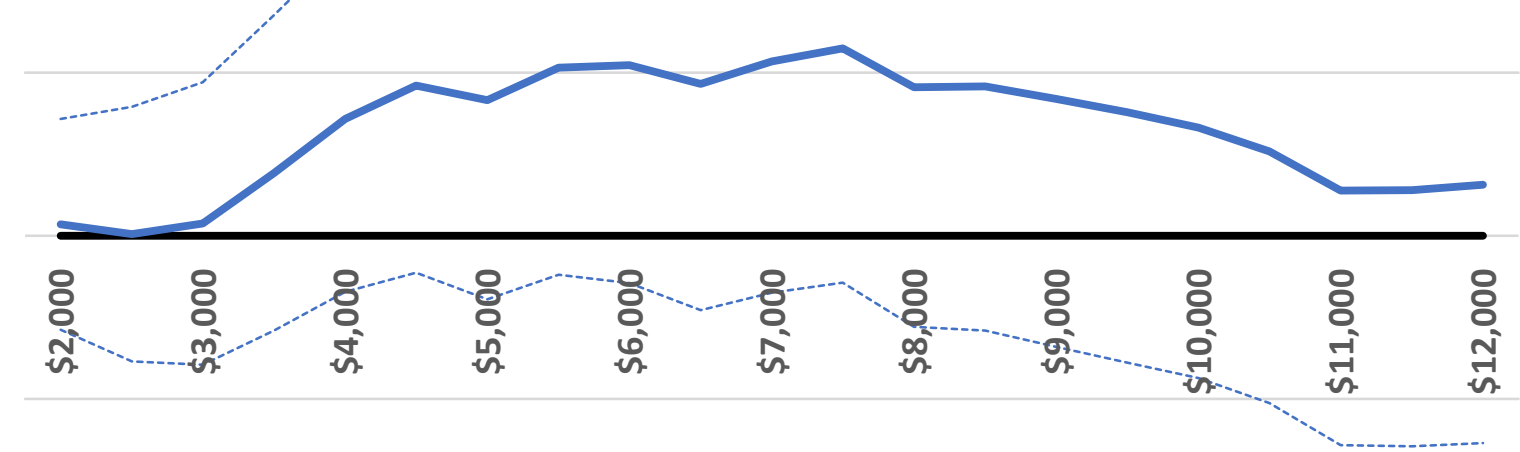

Mean: $94.1 \%$

Mean: $73.4 \%$

Mean: $63.2 \%$

NOTE: The panels show Promise effects [from equation (1) in the text] on the probability, in percentage points, that an individual's real average quarterly earnings exceed the threshold shown (the solid blue lines). Panels A and B treat unmatched quarters as implicit zeros, while Panels $\mathrm{C}$ and D include only matched quarters in creating the dependent variable. Ninety-five percent confidence intervals (the dashed blue lines) are based on standard errors robust to heteroskedasticity, and mean probabilities are labeled for the bottom, middle, and top earnings thresholds. 
Table 1 KPS High School Graduates and Promise (Pseudo-) Eligibility

\begin{tabular}{lrrr}
\hline Year & Graduates & Eligible & Ineligible \\
\hline 2003 & 525 & $0(442)$ & $525(83)$ \\
2004 & 551 & $0(448)$ & $551(103)$ \\
2005 & 392 & $0(345)$ & $392(47)$ \\
$2006\left(1^{\text {st }}\right.$ Promise cohort $)$ & 449 & 368 & 81 \\
2007 & 504 & 435 & 69 \\
2008 & 484 & 415 & 69 \\
2009 & 466 & 390 & 76 \\
2010 & 498 & 431 & 67 \\
2011 & 507 & 433 & 74 \\
2012 & 526 & 461 & 65 \\
2013 & 513 & 472 & 41 \\
Total & 5,415 & 4,640 & 775 \\
\hline
\end{tabular}

NOTE: Numbers represent authors' calculations of the number of graduates receiving high school diplomas (excluding alternative education programs) from KPS and eligibility for the Promise. We determine eligibility (a tuition subsidy of at least 65 percent) based on residence and continuous enrollment from KPS records. See text for eligibility assignment rules. For 2003-2005, the numbers in parentheses indicate the number of students that would (would not) have fulfilled eligibility requirements, even though the Promise did not yet exist. The lower graduate count in 2005 is in large part due to the alternative high school being closed that year.

SOURCE: Authors' calculations from KPS and Kalamazoo Promise administrative data. 
Table 2 KPS Grads and Match Rates in UI Data

\begin{tabular}{lccc|ccc}
\hline $\begin{array}{l}\text { Graduating } \\
\text { class }\end{array}$ & Total & Matched & Match rate & $\begin{array}{c}\text { Mean } \# \\
\text { Total } \\
\text { quarters }\end{array}$ & $\begin{array}{c}\text { quarters } \\
\text { appear }\end{array}$ & $\begin{array}{c}\text { Avg match } \\
\text { rate }\end{array}$ \\
\hline 2003 & 525 & 283 & $53.9 \%$ & 53 & 33.9 & $64.0 \%$ \\
2004 & 551 & 321 & $58.3 \%$ & 53 & 33.1 & $62.5 \%$ \\
2005 & 392 & 224 & $57.1 \%$ & 53 & 34.0 & $64.1 \%$ \\
$2006 *$ & 449 & 362 & $80.6 \%$ & 52 & 32.4 & $62.3 \%$ \\
2007 & 504 & 432 & $85.7 \%$ & 48 & 29.7 & $61.9 \%$ \\
2008 & 484 & 413 & $85.3 \%$ & 44 & 28.0 & $63.6 \%$ \\
2009 & 466 & 405 & $86.9 \%$ & 40 & 26.6 & $66.4 \%$ \\
2010 & 498 & 440 & $88.4 \%$ & 36 & 22.6 & $62.8 \%$ \\
2011 & 507 & 450 & $88.8 \%$ & 32 & 21.1 & $65.8 \%$ \\
2012 & 526 & 478 & $90.9 \%$ & 28 & 19.0 & $67.9 \%$ \\
2013 & 513 & 483 & $94.2 \%$ & 24 & 16.3 & $68.0 \%$ \\
Total & $\mathbf{5 , 4 1 5}$ & $\mathbf{4 , 2 9 1}$ & $\mathbf{7 9 . 2 \%}$ & & & \\
\hline
\end{tabular}

NOTE: Graduating totals by class are shown in Table 1. "Matched" and "Match rate" represent the number of graduates and the percentage of graduates, respectively, by class, that are ever matched in the UI data. (See text for description of UI coverage.) "Total quarters" represents the maximum number of post-high-school-graduation calendar quarters a member of a given class could theoretically be matched in the UI data, "Mean \# quarters appear" is the average number of quarters matched by class, conditional on ever matching, and "Avg match rate" is the percentage of quarters matched.

SOURCE: Authors' calculations from KPS and Michigan UI administrative data. 
Table 3 Characteristics of KPS Grads Overall and Among UI Matched

\begin{tabular}{lccc}
\hline & $\begin{array}{c}\text { High school } \\
\text { grads }\end{array}$ & UI match & $\begin{array}{c}\text { Quarter-person } \\
\text { matched }\end{array}$ \\
\hline Male & $47.1 \%$ & $50.8 \%$ & $50.6 \%$ \\
Black & $41.1 \%$ & $43.9 \%$ & $44.4 \%$ \\
Hispanic & $7.0 \%$ & $6.3 \%$ & $5.8 \%$ \\
Other race/ethnicity & $51.9 \%$ & $49.8 \%$ & $49.7 \%$ \\
Free/reduced-price lunch & $50.7 \%$ & $53.3 \%$ & $53.1 \%$ \\
HS \#1 & $51.3 \%$ & $51.6 \%$ & $51.5 \%$ \\
HS \#2 & $40.3 \%$ & $39.7 \%$ & $40.3 \%$ \\
GPA $<2.0$ & $22.1 \%$ & $24.1 \%$ & $23.5 \%$ \\
GPA 2.0-2.5 & $18.0 \%$ & $19.2 \%$ & $20.5 \%$ \\
GPA 2.5-3.0 & $19.1 \%$ & $19.4 \%$ & $21.1 \%$ \\
GPA 3.0-3.5 & $19.7 \%$ & $19.0 \%$ & $18.7 \%$ \\
GPA $>3.5$ & $21.1 \%$ & $18.3 \%$ & $16.2 \%$ \\
No college $\leq 12$ months of HS grad & $23.1 \%$ & $20.2 \%$ & $20.6 \%$ \\
Start at local 2-year (KVCC) & $29.9 \%$ & $32.8 \%$ & $36.4 \%$ \\
Start at local 4-year (WMU) & $19.9 \%$ & $20.5 \%$ & $22.0 \%$ \\
Start at Michigan State & $6.7 \%$ & $7.2 \%$ & $5.5 \%$ \\
Start at University of Michigan & $4.5 \%$ & $4.4 \%$ & $3.2 \%$ \\
Start elsewhere & $16.0 \%$ & $14.9 \%$ & $12.4 \%$ \\
Promise-eligible & $88.8 \%$ & $90.6 \%$ & $90.6 \%$ \\
\hline
\end{tabular}

NOTE: The "High school grads" column includes the 5,415 individuals from the "Total" column in Table 2, the "UI match" column includes the 4,291 individual from the "Matched" column in Table 2, and the "Quarter-person matched" column includes the 4,291 individuals from the "Matched" column in Table 2 but weighted by the number of total calendar quarters with a record in the UI data.

SOURCE: Authors' calculations from KPS, NSC, and Michigan UI administrative data. 
Table 4 Promise Effects on Employment

\begin{tabular}{|c|c|c|c|c|c|c|}
\hline & (1) & (2) & (3) & (4) & (5) & (6) \\
\hline & \multicolumn{3}{|c|}{ Full sample } & \multicolumn{3}{|c|}{ High-match sample } \\
\hline & $1-3$ years & $4-6$ years & $7-10$ years & $1-3$ years & $4-6$ years & $7-10$ years \\
\hline \multicolumn{7}{|l|}{ Panel A: $\geq 2$ quarters } \\
\hline & $\begin{array}{c}0.0168 \\
(0.0396)\end{array}$ & $\begin{array}{c}0.0102 \\
(0.0388)\end{array}$ & $\begin{array}{c}0.0040 \\
(0.0405)\end{array}$ & $\begin{array}{c}0.0120 \\
(0.0571)\end{array}$ & $\begin{array}{l}-0.0125 \\
(0.0551)\end{array}$ & $\begin{array}{c}0.0175 \\
(0.0583)\end{array}$ \\
\hline Mean dep. variable & 0.375 & 0.393 & 0.376 & 0.445 & 0.487 & 0.472 \\
\hline $\mathrm{R}^{2}$ & 0.055 & 0.096 & 0.092 & 0.045 & 0.081 & 0.075 \\
\hline $\mathrm{N}$ & 14,641 & 16,242 & 16,516 & 7,662 & 8,385 & 8,118 \\
\hline \multicolumn{7}{|l|}{ Panel B: $\geq 3$ quarters } \\
\hline & $\begin{array}{c}0.0190 \\
(0.0292)\end{array}$ & $\begin{array}{c}0.0078 \\
(0.0373)\end{array}$ & $\begin{array}{c}0.0143 \\
(0.0396)\end{array}$ & $\begin{array}{c}0.0184 \\
(0.0414)\end{array}$ & $\begin{array}{l}-0.0171 \\
(0.0528)\end{array}$ & $\begin{array}{l}0.0137 \\
(.0570)\end{array}$ \\
\hline Mean dep. variable & 0.174 & 0.348 & 0.344 & 0.212 & 0.432 & 0.431 \\
\hline $\mathrm{R}^{2}$ & 0.082 & 0.081 & 0.079 & 0.083 & 0.071 & 0.067 \\
\hline $\mathrm{N}$ & 14,641 & 16,242 & 16,516 & 7,662 & 8,385 & 8,118 \\
\hline \multicolumn{7}{|l|}{ Panel C: $\geq 4$ quarters } \\
\hline & $\begin{array}{c}0.0168 \\
(0.0265)\end{array}$ & $\begin{array}{c}0.0162 \\
(0.0343)\end{array}$ & $\begin{array}{c}0.0095 \\
(0.0356)\end{array}$ & $\begin{array}{c}0.0229 \\
(0.0376)\end{array}$ & $\begin{array}{c}0.0039 \\
(0.0490)\end{array}$ & $\begin{array}{c}0.0176 \\
(0.0520)\end{array}$ \\
\hline Mean dep. variable & 0.137 & 0.281 & 0.303 & 0.166 & 0.350 & 0.375 \\
\hline $\mathrm{R}^{2}$ & 0.060 & 0.062 & 0.068 & 0.062 & 0.058 & 0.080 \\
\hline $\mathrm{N}$ & 14,641 & 16,242 & 16,516 & 7,662 & 8,385 & 8,118 \\
\hline
\end{tabular}

NOTE: Each cell represents a point estimate and the standard error from a separate regression. Standard errors robust to heteroskedasticity and clustered by individual are in parentheses; each observation is a person-year. The dependent variable is a binary indicator for whether an individual has positive earnings in at least the specified number of quarters (by panel) in a year. ${ }^{* *},{ }^{* *}$, and $*$ indicate statistical significance at the $0.01,0.05$, and 0.10 levels, respectively.

SOURCE: Authors' calculations from KPS, NSC, and Michigan UI administrative data. 
Table 5 Promise Effects on Earnings Levels

\begin{tabular}{|c|c|c|c|c|c|c|}
\hline & $(1)$ & $(2)$ & (3) & (4) & $(5)$ & (6) \\
\hline & \multicolumn{3}{|c|}{ Full sample } & \multicolumn{3}{|c|}{ High-match sample } \\
\hline & $1-3$ years & $4-6$ years & $7-10$ years & $1-3$ years & $4-6$ years & $7-10$ years \\
\hline \multicolumn{7}{|c|}{ Panel A: All person-quarters } \\
\hline & $\begin{array}{c}-90.7 \\
(145.6)\end{array}$ & $\begin{array}{c}-14.3 \\
(206.5)\end{array}$ & $\begin{array}{c}488.8 \\
(315.9)\end{array}$ & $\begin{array}{l}-148.9 \\
(216.8)\end{array}$ & $\begin{array}{c}-88.8 \\
(296.2)\end{array}$ & $\begin{array}{c}245.0 \\
(425.6)\end{array}$ \\
\hline Mean dep. variable & 1137 & 1615 & 2441 & 1453 & 1926 & 2770 \\
\hline $\mathrm{R}^{2}$ & 0.033 & 0.065 & 0.056 & 0.027 & 0.066 & 0.059 \\
\hline $\mathrm{N}$ & 14,641 & 16,242 & 16,516 & 7,662 & 8,385 & 8,118 \\
\hline \multicolumn{7}{|c|}{ Panel B: Only matched person-quarters } \\
\hline & $\begin{array}{l}-112.8 \\
(233.5)\end{array}$ & $\begin{array}{l}-293.7 \\
(295.4)\end{array}$ & $\begin{array}{c}388.8 \\
(538.9)\end{array}$ & $\begin{array}{l}-246.0 \\
(305.4)\end{array}$ & $\begin{array}{l}-134.5 \\
(395.9)\end{array}$ & $\begin{array}{c}30.7 \\
(593.7)\end{array}$ \\
\hline Mean dep. variable & 2738 & 4029 & 6354 & 3007 & 3941 & 5708 \\
\hline $\mathrm{R}^{2}$ & 0.047 & 0.036 & 0.056 & 0.055 & 0.048 & 0.045 \\
\hline $\mathrm{N}$ & 9,428 & 10,327 & 9,263 & 5,445 & 5,978 & 5,365 \\
\hline
\end{tabular}

NOTE: Each cell represents a point estimate and the standard error from a separate regression. Standard errors robust to heteroskedasticity and clustered by individual are in parentheses; each observation is a person-year. The dependent variable is the inflation-adjusted (\$2018 PCE) average quarterly earnings of the individual in a year. Panel A uses a sample that treats missing person-quarters as implicit zeros, while panel B uses a sample that includes only matched person-quarters with positive earnings. $* * *, * *$, and * indicate statistical significance at the $0.01,0.05$, and 0.10 levels, respectively.

SOURCE: Authors' calculations from KPS, NSC, and Michigan UI administrative data. 
Table 6 Promise Effects on Location Choice

\begin{tabular}{|c|c|c|c|c|c|c|}
\hline & $(1)$ & (2) & (3) & (4) & $(5)$ & (6) \\
\hline & \multicolumn{3}{|c|}{ Full sample } & \multicolumn{3}{|c|}{ High-match sample } \\
\hline & $1-3$ years & $4-6$ years & $7-10$ years & $1-3$ years & $4-6$ years & $7-10$ years \\
\hline \multicolumn{7}{|l|}{ Panel A: $\leq 5$ miles } \\
\hline & $\begin{array}{c}0.088 \\
(0.068)\end{array}$ & $\begin{array}{l}0.132 * \\
(0.069)\end{array}$ & $\begin{array}{c}0.091 \\
(0.082)\end{array}$ & $\begin{array}{c}0.032 \\
(0.086)\end{array}$ & $\begin{array}{c}0.091 \\
(0.089)\end{array}$ & $\begin{array}{c}0.064 \\
(0.104)\end{array}$ \\
\hline Mean dep. variable & 0.604 & 0.586 & 0.582 & 0.617 & 0.603 & 0.613 \\
\hline $\mathrm{R}^{2}$ & 0.043 & 0.050 & 0.053 & 0.055 & 0.060 & 0.053 \\
\hline $\mathrm{N}$ & 7,308 & 5,888 & 4,668 & 4,215 & 3,465 & 2,986 \\
\hline \multicolumn{7}{|l|}{$\underline{\text { Panel B: } \leq 10 \text { miles }}$} \\
\hline & $\begin{array}{c}0.093 \\
(0.058)\end{array}$ & $\begin{array}{c}0.174 * * * \\
(0.056)\end{array}$ & $\begin{array}{l}0.122 * \\
(0.066)\end{array}$ & $\begin{array}{c}0.050 \\
(0.072)\end{array}$ & $\begin{array}{c}0.162 * * \\
(0.071)\end{array}$ & $\begin{array}{c}0.093 \\
(0.085)\end{array}$ \\
\hline Mean dep. variable & 0.804 & 0.788 & 0.786 & 0.847 & 0.844 & 0.844 \\
\hline $\mathrm{R}^{2}$ & 0.047 & 0.050 & 0.057 & 0.057 & 0.060 & 0.058 \\
\hline $\mathrm{N}$ & 7,308 & 5,888 & 4,668 & 4,215 & 3,465 & 2,986 \\
\hline \multicolumn{7}{|l|}{$\underline{\text { Panel } C:} \leq 20$ miles } \\
\hline & $\begin{array}{c}0.060 \\
(0.056)\end{array}$ & $\begin{array}{c}0.152 * * * \\
(0.051)\end{array}$ & $\begin{array}{c}0.114 * \\
(0.060)\end{array}$ & $\begin{array}{c}0.046 \\
(0.069)\end{array}$ & $\begin{array}{c}0.191 * * * \\
(0.061)\end{array}$ & $\begin{array}{l}0.141 * \\
(0.074)\end{array}$ \\
\hline Mean dep. variable & 0.854 & 0.838 & 0.836 & 0.896 & 0.891 & 0.890 \\
\hline $\mathrm{R}^{2}$ & 0.037 & 0.036 & 0.042 & 0.048 & 0.052 & 0.056 \\
\hline $\mathrm{N}$ & 7,308 & 5,888 & 4,668 & 4,215 & 3,465 & 2,986 \\
\hline \multicolumn{7}{|l|}{ Panel D: $\leq 50$ miles } \\
\hline & $\begin{array}{c}0.041 \\
(0.045)\end{array}$ & $\begin{array}{c}0.103 * * \\
(0.041)\end{array}$ & $\begin{array}{c}0.078 \\
(0.049)\end{array}$ & $\begin{array}{c}0.030 \\
(0.054)\end{array}$ & $\begin{array}{c}0.126^{* * *} \\
(0.047)\end{array}$ & $\begin{array}{c}0.083 \\
(0.062)\end{array}$ \\
\hline Mean dep. variable & 0.905 & 0.894 & 0.890 & 0.935 & 0.933 & 0.930 \\
\hline$R^{2}$ & 0.029 & 0.029 & 0.030 & 0.031 & 0.037 & 0.037 \\
\hline$N$ & 7,308 & 5,888 & 4,668 & 4,215 & 3,465 & 2,986 \\
\hline
\end{tabular}

NOTE: Each cell represents a point estimate and the standard error from a separate regression. Standard errors robust to heteroskedasticity and clustered by individual are in parentheses; each observation is a person-year. The dependent variable is a binary indicator for whether the mode of an individual's residential ZIP code in a year was within the specified distance (by panel) from Kalamazoo's central business district. ***, **, and * indicate statistical significance at the $0.01,0.05$, and 0.10 levels, respectively.

SOURCE: Authors' calculations from KPS, NSC, and Michigan UI administrative data. 
Table 7 Promise Effects by Sex, Race, and Family Income Background, 7-10 years after High School Graduation

\begin{tabular}{|c|c|c|c|c|c|c|}
\hline & $(1)$ & $(2)$ & (3) & (4) & $(5)$ & $(6)$ \\
\hline & Men & Women & Whites & Minorities & Non-FRL & FRL \\
\hline \multicolumn{7}{|c|}{ Panel A: $\geq 4$ quarters employed } \\
\hline & $\begin{array}{c}0.0219 \\
(0.0545)\end{array}$ & $\begin{array}{c}0.0056 \\
(0.0464)\end{array}$ & $\begin{array}{c}0.0558 \\
(0.0594)\end{array}$ & $\begin{array}{l}-0.0009 \\
(0.0444)\end{array}$ & $\begin{array}{c}0.0117 \\
(0.0568)\end{array}$ & $\begin{array}{c}0.0308 \\
(0.0472)\end{array}$ \\
\hline Mean dep. variable & 0.380 & 0.235 & 0.300 & 0.308 & 0.315 & 0.282 \\
\hline $\mathrm{R}^{2}$ & 0.061 & 0.087 & 0.063 & 0.092 & 0.052 & 0.101 \\
\hline $\mathrm{N}$ & 7,764 & 8,752 & 8,280 & 8,236 & 8,550 & 7,946 \\
\hline \multicolumn{7}{|c|}{ Panel B: Avg qtrly earnings } \\
\hline & $\begin{array}{c}576.6 \\
(573.7)\end{array}$ & $\begin{array}{c}470.2 \\
(349.9)\end{array}$ & $\begin{array}{c}920.4^{*} \\
(537.0)\end{array}$ & $\begin{array}{c}306.4 \\
(387.7)\end{array}$ & $\begin{array}{c}730.1 \\
(545.1)\end{array}$ & $\begin{array}{c}467.6 \\
(395.6)\end{array}$ \\
\hline Mean dep. variable & 3,276 & 1,702 & 2,577 & 2,250 & 2,616 & 2,111 \\
\hline $\mathrm{R}^{2}$ & 0.043 & 0.079 & 0.062 & 0.073 & 0.050 & 0.084 \\
\hline $\mathrm{N}$ & 7,764 & 8,752 & 8,280 & 8,236 & 8,550 & 7,946 \\
\hline \multicolumn{7}{|c|}{ Panel C: Earnings $\geq \$ 4000$} \\
\hline & $\begin{array}{c}0.028 \\
(0.053)\end{array}$ & $\begin{array}{c}0.059 \\
(0.043)\end{array}$ & $\begin{array}{c}0.050 \\
(0.056)\end{array}$ & $\begin{array}{c}0.045 \\
(0.043)\end{array}$ & $\begin{array}{c}0.049 \\
(0.055)\end{array}$ & $\begin{array}{c}0.053 \\
(0.044)\end{array}$ \\
\hline Mean dep. variable & 0.322 & 0.177 & 0.248 & 0.241 & 0.259 & 0.218 \\
\hline $\mathrm{R}^{2}$ & 0.045 & 0.087 & 0.072 & 0.065 & 0.051 & 0.082 \\
\hline $\mathrm{N}$ & 7,764 & 8,752 & 8,280 & 8,236 & 8,550 & 7,946 \\
\hline \multicolumn{7}{|l|}{ Panel D: $\leq 10$ miles } \\
\hline & $\begin{array}{c}0.202 * * \\
(0.099)\end{array}$ & $\begin{array}{c}0.028 \\
(0.089)\end{array}$ & $\begin{array}{l}0.226^{*} \\
(0.122)\end{array}$ & $\begin{array}{c}0.056 \\
(0.075)\end{array}$ & $\begin{array}{c}0.062 \\
(0.116)\end{array}$ & $\begin{array}{c}0.157 * * \\
(0.075)\end{array}$ \\
\hline Mean dep. variable & 0.757 & 0.825 & 0.726 & 0.895 & 0.741 & 0.870 \\
\hline $\mathrm{R}^{2}$ & 0.061 & 0.079 & 0.060 & 0.035 & 0.043 & 0.064 \\
\hline $\mathrm{N}$ & 2,457 & 2,211 & 1,905 & 2,763 & 2,081 & 2,587 \\
\hline
\end{tabular}

NOTE: Each cell represents a point estimate and the standard error from a separate regression. Standard errors robust to heteroskedasticity and clustered by individual are in parentheses; each observation is a person-year. The dependent variables vary by panel. "FRL" includes individuals who were eligible for free or reduced-price lunch in high school and indicates lower family income. ${ }^{* *}, * *$, and $*$ indicate statistical significance at the $0.01,0.05$, and 0.10 levels, respectively.

SOURCE: Authors' calculations from KPS, NSC, and Michigan UI administrative data. 


\section{APPENDIX}

\section{A. UI Data Processing}

The UI data we received cover the period from the first quarter of 2006 through the first quarter of 2019 and contain one observation per individual per covered employer per calendar quarter. We collapse these data to the person-quarter data by summing earnings across employers (for individuals with more than one) within a given calendar quarter. (For ZIP code, we take the first mode across quarters.) Earnings are then adjusted to year 2018 dollars using the personal consumption expenditures deflator. We then merged these data to our education records (from Kalamazoo Public Schools, the Kalamazoo Promise, and the National Student Clearinghouse) using a linked student ID variable.

Using timing of high school graduation, we convert earnings and ZIP code measures from a calendar-quarter basis to a quarters-elapsed-since-high-school-graduation basis. Because quarters in which an individual has no employment record are not present, we rectangularize the data by filling in these quarters (with implicit zeros) so that all quarters elapsed since high school (through the maximum shown in Table 2) are populated. (These filled-in quarters are also flagged, as their use varies based on construction of the chosen sample.) Although we observe the first quarter elapsed since high school graduation for the classes of 2006-2013, observations for the class of 2005 start with quarter 3, observations for the class of 2004 start with quarter 7 , and observations for the class of 2003 start with quarter 11.

The quarters-elapsed measures are then further collapsed to year-elapsed measures as described in the main text. 


\section{B. Telephone Interview Instrument}

We are interested in learning about your employment experiences and really appreciate your help.

We have a series of questions that will take roughly 15-20 minutes of your time. All reports that we generate from these questions and your answers will be presented in an aggregate format, meaning that all information gathered is strictly confidential (with our Upjohn Institute researcher team and Promise staff) and your name will never be mentioned in our reports.

Thank you for your time and your input.

1. Confirm high school graduation year

2. In what city and state are you currently living?

3. Where did you first attend college or receive training following your high school graduation?

4. How did you decide to attend this college, apprenticeship, or trade school? (interview prompts if needed: using all that apply but highlight the most important factor):

Proximity to home

Farthest from home

Attracted to a specific training program

Friend or relative attends the school

They offered a scholarship

Wanted to play sports there

Strong academic reputation

Strong arts reputation

Family legacy attendance

Other

5. Did you attend any training, colleges, or universities after this one? If so, please list them in chronological order:

1.

2.

3.

6. What was your undergraduate major or field of training at the time you finished or left your college or training program?

7. Are you currently employed? If so, what is the name and industry of your employer and your job title? What is the city and state of your employment? How long have you worked here?

8. Have you had other jobs since finishing college or your training program? If so, could you list your job title, employer, and city and state, starting with the first job since leaving college or training?

$1^{\text {st }}$ job

$2^{\text {nd }}$ job 
9. Did you have any internships or other significant work experiences while in college? Please list the job title, employer, and location of each such experience. Dates of these experiences, i.e. Junior year, rising senior summer, etc.

1.

2.

3.

10. How did you look for your first job after college/training? (Interview prompts: monster or other internet search, job boards, school placement office, family/friends, Facebook, prior work experience, etc.)

How long after graduation did you get this first job? (prompts: did the process begin before you graduated from college? In the summer? Later?)

How did you look for your current job, if it is different from your first job search?

11. When you were searching for jobs, did you actively search for a job in or around Kalamazoo? In Michigan?

[If no, why not?]

12. What were your top two reasons for taking your first job after college?

Your current or most recent job (if different)? (Interview prompts: pay, interest fit, location, benefits, connection to prior work/internship).

13. Thinking about your current or most recent employment, Do you consider this a full-time job?

14. Remembering that all responses will remain anonymous and never be individually identified, what are your annual earnings from this job?

Less than $\$ 19,999$

20K-\$29,999

$30 \mathrm{~K}-39,999$

$40 \mathrm{~K}-49,999$

$50 \mathrm{~K}-59,999$

$60 \mathrm{~K}-74,999$

75K-99,999

$100 \mathrm{~K}+$

15. Do you have any current plans to move?

If so, where would you move?

What factors guide your decision? 
We are interested in expanding the number of KPS grads included in this study and would appreciate your help. Could you provide the name and contact information of 3 more people that you know that graduated from KPS and are employed out of state?

1.

2.

3.

Thank you again for your time. Are there any questions that you have for me?

As I move away from the confidential portion of my questions, I have one last question. The Kalamazoo Promise staff are reaching out to KPS graduates interested in being part of the Promise2Promise Network they are creating? This effort connects Promise alumni with Promise students to find jobs, internships and network, among other things. It will be on the LinkedIn platform. Would you be interested in them contacting you for the Promise2Promise Network?

Name:

Best contact method:

Are you currently on LinkedIn? 


\section{Figure A1 Promise Effects on Earnings Distribution: High-Match Sample}

A. 4-6 years post-high school graduation

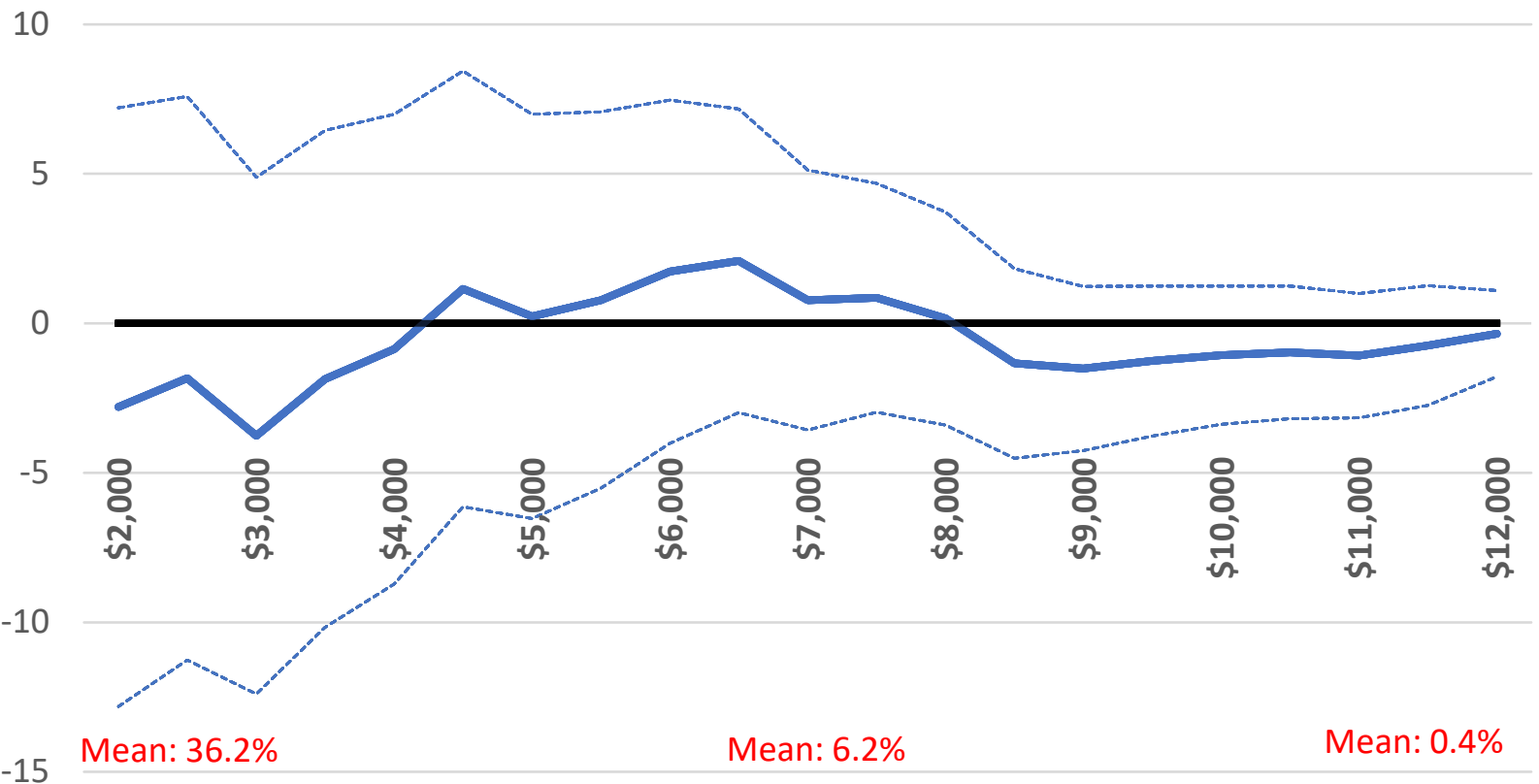

B. 7-10 years post-high school graduation

20

15

10

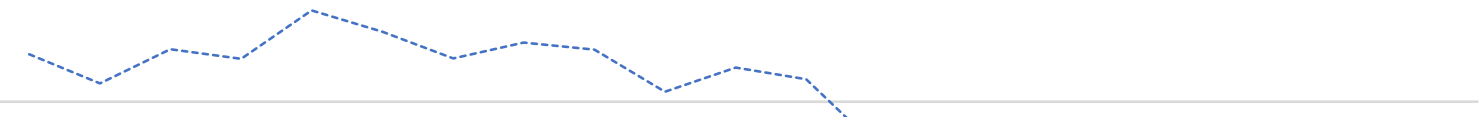

5

0

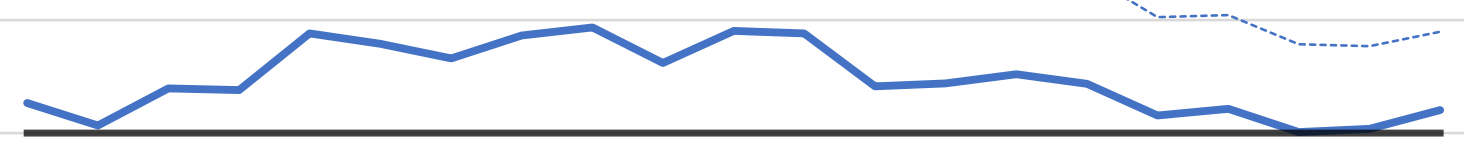

$-5$

$-10$

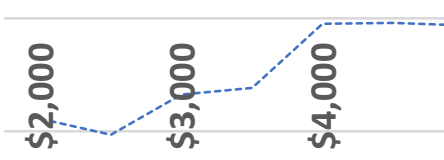

Mean: $40.1 \%$

Mean: $14.3 \%$

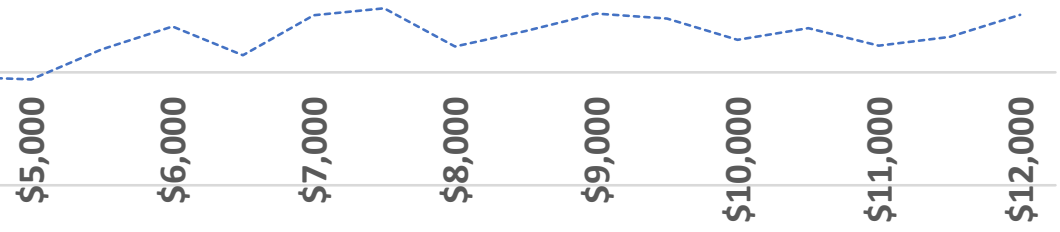

Mean: 3.0\% 
C. 4-6 years post-high school graduation: Only matched person-quarters sample

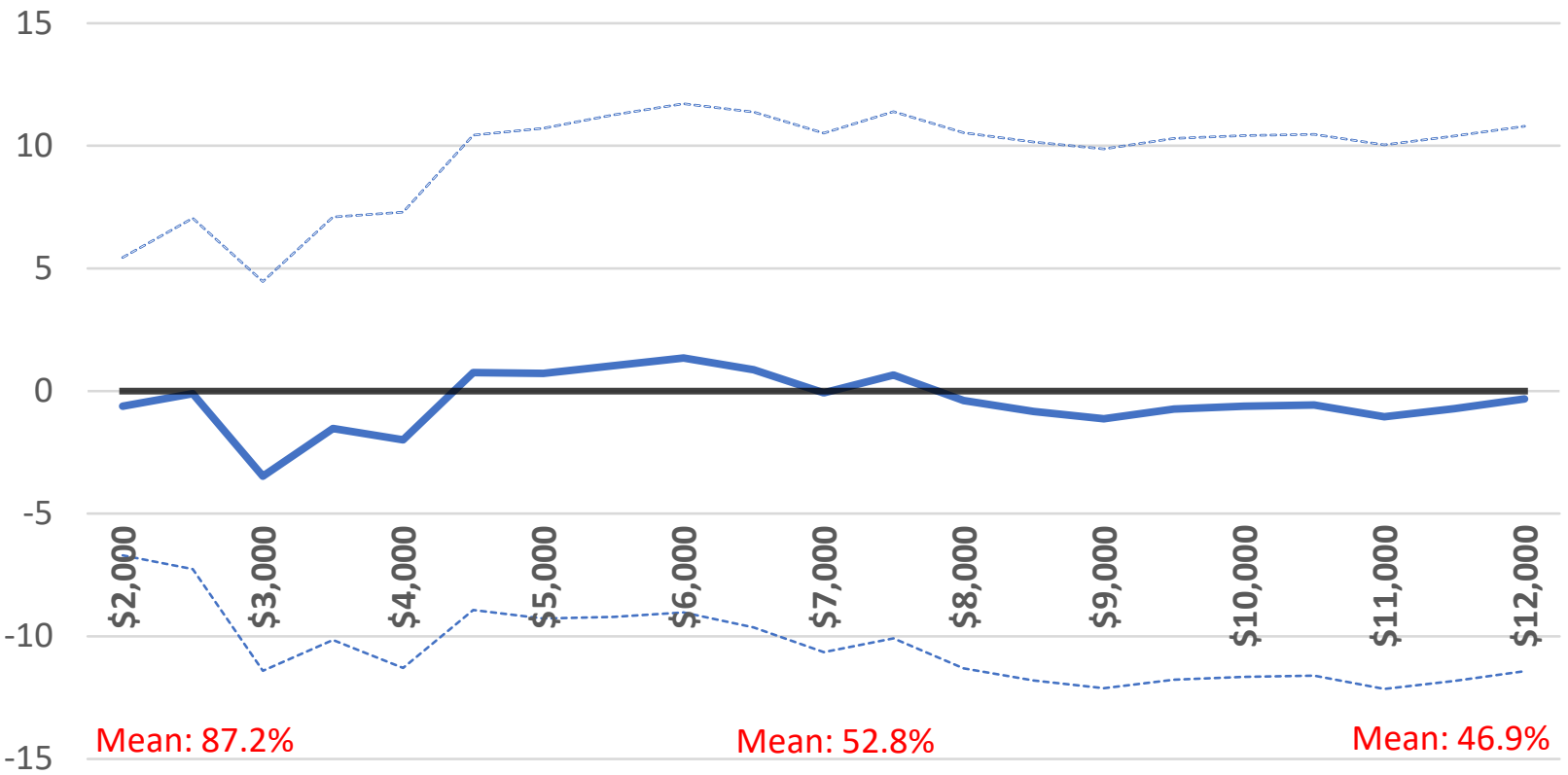

D. 7-10 years post-high school graduation: Only matched person-quarters sample

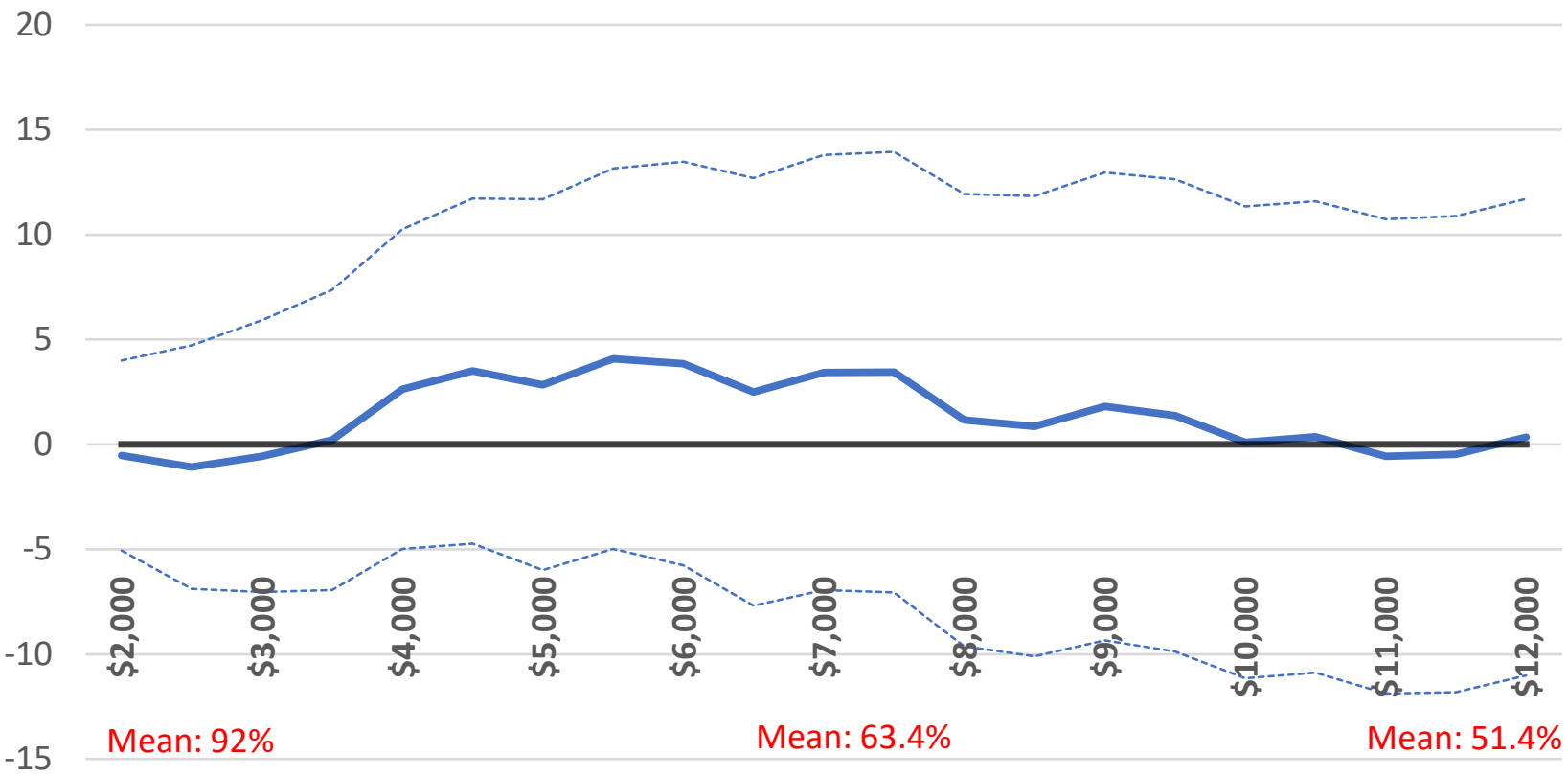

NOTE: See note to Figure 3. Unlike that figure, this appendix figure shows estimates for the high-match-rate sample. 
Table A1 Descriptive Statistics of the Sample

\begin{tabular}{lccrrrrr}
\hline & \multicolumn{9}{c}{ Before } & \multicolumn{2}{c}{ After } & & DD \\
Variable & All & Eligibles & Ineligibles & Eligibles & Ineligibles & \multicolumn{1}{c}{ DD } & (std. err.) \\
\hline Demographics & & & & & & & \\
$\quad$ Male & 0.471 & 0.470 & 0.442 & 0.480 & 0.432 & 0.0206 & $(0.0423)$ \\
Black & 0.411 & 0.346 & 0.481 & 0.403 & 0.581 & -0.0436 & $(0.0421)$ \\
Asian & 0.026 & 0.017 & 0.056 & 0.026 & 0.031 & 0.0339 & $(0.0174)$ \\
Hispanic & 0.070 & 0.049 & 0.086 & 0.074 & 0.083 & 0.0277 & $(0.0231)$ \\
White & 0.485 & 0.584 & 0.369 & 0.487 & 0.295 & -0.0233 & $(0.0407)$ \\
Subsidized lunch & 0.507 & 0.338 & 0.528 & 0.534 & 0.710 & 0.0130 & $(0.0413)$ \\
High school 1 & 0.513 & 0.491 & 0.399 & 0.530 & 0.507 & -0.0685 & $(0.0420)$ \\
High school 2 & 0.403 & 0.446 & 0.373 & 0.401 & 0.325 & 0.0037 & $(0.0410)$ \\
$N$ & 5,415 & 1,235 & 233 & 3,405 & 542 & & \\
\hline
\end{tabular}

NOTE: Authors' calculations of characteristics of KPS graduates for classes of 2003 through 2013 (excluding alternative education). Eligibility calculated based on Promise rules. "Before" represents cohorts 2003 through 2005; "After" represents cohorts 2006 through 2013. "DD" represents the difference between eligibles after and before the Promise and ineligibles after and before the Promise. Standard errors robust to heteroskedasticity are in parentheses. SOURCE: Authors' calculations from KPS and Kalamazoo Promise administrative data. 
Table A2 KPS Grads and Match Rates in UI Data, by Eligibility

\begin{tabular}{lcccccc}
\hline $\begin{array}{l}\text { Graduating } \\
\text { class }\end{array}$ & $\begin{array}{c}\text { Eligible } \\
\text { total }\end{array}$ & $\begin{array}{c}\text { Eligible } \\
\text { match rate }\end{array}$ & $\begin{array}{c}\text { Eligible qtr } \\
\text { match rate }\end{array}$ & $\begin{array}{c}\text { Ineligible } \\
\text { total }\end{array}$ & $\begin{array}{c}\text { Ineligible } \\
\text { match rate }\end{array}$ & $\begin{array}{c}\text { Ineligible qtr } \\
\text { match rate }\end{array}$ \\
\hline 2003 & 442 & $55.7 \%$ & $64.1 \%$ & 83 & $44.6 \%$ & $63.4 \%$ \\
2004 & 448 & $60.0 \%$ & $64.4 \%$ & 103 & $50.5 \%$ & $52.7 \%$ \\
2005 & 345 & $58.0 \%$ & $65.1 \%$ & 47 & $51.1 \%$ & $55.7 \%$ \\
$2006 *$ & 388 & $82.0 \%$ & $62.7 \%$ & 61 & $72.1 \%$ & $59.3 \%$ \\
2007 & 462 & $87.2 \%$ & $62.3 \%$ & 42 & $69.0 \%$ & $56.4 \%$ \\
2008 & 430 & $87.0 \%$ & $63.2 \%$ & 54 & $72.2 \%$ & $67.6 \%$ \\
2009 & 420 & $88.3 \%$ & $66.5 \%$ & 46 & $73.9 \%$ & $65.7 \%$ \\
2010 & 452 & $89.2 \%$ & $63.4 \%$ & 46 & $80.4 \%$ & $57.1 \%$ \\
2011 & 459 & $88.9 \%$ & $65.4 \%$ & 48 & $87.5 \%$ & $69.2 \%$ \\
2012 & 477 & $91.2 \%$ & $68.5 \%$ & 49 & $87.8 \%$ & $61.0 \%$ \\
2013 & 483 & $95.5 \%$ & $68.1 \%$ & 30 & $73.3 \%$ & $67.8 \%$ \\
& & & & 609 & $\mathbf{6 6 . 2 \%}$ & \\
\hline
\end{tabular}

NOTE: See notes to Table 2.

SOURCE: Authors' calculations from KPS and Michigan UI administrative data. 
Table A3 Promise Effects on Employment (Attached Sample)

\begin{tabular}{|c|c|c|c|}
\hline & $(1)$ & $(2)$ & $(3)$ \\
\hline & \multicolumn{3}{|c|}{ Full sample } \\
\hline & $1-3$ years & $4-6$ years & $7-10$ years \\
\hline \multicolumn{4}{|l|}{ Panel A: $\geq 2$ quarters } \\
\hline & $\begin{array}{l}-0.0406 \\
(0.0397)\end{array}$ & $\begin{array}{l}-0.0447 \\
(0.0305)\end{array}$ & $\begin{array}{c}-0.0043 \\
(0.0242)\end{array}$ \\
\hline Mean dep. variable & 0.798 & 0.886 & 0.917 \\
\hline $\mathrm{R}^{2}$ & 0.012 & 0.013 & 0.007 \\
\hline $\mathrm{N}$ & 9,428 & 10,327 & 9,263 \\
\hline \multicolumn{4}{|l|}{ Panel B: $\geq 3$ quarters } \\
\hline & $\begin{array}{l}-0.0426 \\
(0.0349)\end{array}$ & $\begin{array}{l}-0.0582 \\
(0.0392)\end{array}$ & $\begin{array}{c}0.0208 \\
(0.0324)\end{array}$ \\
\hline Mean dep. variable & 0.370 & 0.783 & 0.841 \\
\hline $\mathrm{R}^{2}$ & 0.077 & 0.016 & 0.012 \\
\hline $\mathrm{N}$ & 9,428 & 10,327 & 9,263 \\
\hline \multicolumn{4}{|l|}{ Panel C: $\geq 4$ quarters } \\
\hline & $\begin{array}{l}-0.0358 \\
(0.0386)\end{array}$ & $\begin{array}{l}-0.0295 \\
(0.0455)\end{array}$ & $\begin{array}{c}0.0245 \\
(0.0409)\end{array}$ \\
\hline Mean dep. variable & 0.292 & 0.632 & 0.741 \\
\hline $\mathrm{R}^{2}$ & 0.051 & 0.033 & 0.148 \\
\hline $\mathrm{N}$ & 9,428 & 10,327 & 9,263 \\
\hline
\end{tabular}

NOTE: Each cell represents a point estimate and the standard error from a separate regression. Standard errors robust to heteroskedasticity and clustered by individual are in parentheses; each observation is a person-year. The dependent variable is a binary indicator for whether an individual has positive earnings in at least the specified number of quarters (by panel) in a year. ***,**, and * indicate statistical significance at the $0.01,0.05$, and 0.10 levels, respectively. Unlike Table 4, the sample here is conditioned on at least one matched quarter per year. SOURCE: Authors' calculations from KPS, NSC, and Michigan UI administrative data. 
Table A4 Promise Effects on Earnings Levels (Attached Sample)

\begin{tabular}{lccc}
\hline & $(1)$ & $(2)$ & $(3)$ \\
& & Full sample & \\
& $1-3$ years & $4-6$ years & $7-10$ years \\
\hline Panel A: All person-quarters & & & \\
& -221.6 & -356.8 & 472.1 \\
& $(231.1)$ & $(305.7)$ & $(533.9)$ \\
Mean dep. Variable & 2416 & 3637 & 5964 \\
$\mathrm{R}^{2}$ & 0.049 & 0.033 & 0.053 \\
$\mathrm{~N}$ & 9,428 & 10,327 & 9,263 \\
\hline Panel B: Only matched person-quarters & & & \\
& -112.8 & -293.7 & 388.8 \\
& $(233.5)$ & $(295.4)$ & $(538.9)$ \\
Mean dep. Variable & & & 6354 \\
$\mathrm{R}^{2}$ & 2738 & 4029 & 0.056 \\
$\mathrm{~N}$ & 0.047 & 0.036 & 9,263 \\
\hline
\end{tabular}

NOTE: Each cell represents a point estimate and the standard error from a separate regression. Standard errors robust to heteroskedasticity and clustered by individual are in parentheses; each observation is a person-year. The dependent variable is the inflation-adjusted (\$2018 PCE) average quarterly earnings of the individual in a year. Panel A uses a sample that treats missing person-quarters as implicit zeros, while panel B uses a sample that includes only matched person-quarters with positive earnings. $* * *, * *$, and $*$ indicate statistical significance at the $0.01,0.05$, and 0.10 levels, respectively. Unlike Table 5 , the sample here is conditioned on at least one matched quarter per year.

SOURCE: Authors' calculations from KPS, NSC, and Michigan UI administrative data. 
Table A5 Promise Effects on Location Choice (Attached Sample)

\begin{tabular}{|c|c|c|c|}
\hline & $(1)$ & $(2)$ & $(3)$ \\
\hline & \multicolumn{3}{|c|}{ Full sample } \\
\hline & $1-3$ years & $4-6$ years & $7-10$ years \\
\hline \multicolumn{4}{|l|}{ Panel A: $\leq 5$ miles } \\
\hline & $\begin{array}{c}0.090 \\
(0.068)\end{array}$ & $\begin{array}{l}0.135^{*} \\
(0.069)\end{array}$ & $\begin{array}{c}0.091 \\
(0.082)\end{array}$ \\
\hline Mean dep. variable & 0.601 & 0.583 & 0.584 \\
\hline $\mathrm{R}^{2}$ & 0.043 & 0.049 & 0.053 \\
\hline $\mathrm{N}$ & 7,258 & 5,849 & 4,645 \\
\hline \multicolumn{4}{|l|}{ Panel B: $\leq 10$ miles } \\
\hline & $\begin{array}{l}0.096 * \\
(0.059)\end{array}$ & $\begin{array}{c}0.170 * * * \\
(0.056)\end{array}$ & $\begin{array}{l}0.120 * \\
(0.066)\end{array}$ \\
\hline Mean dep. variable & 0.802 & 0.787 & 0.788 \\
\hline $\mathrm{R}^{2}$ & 0.048 & 0.050 & 0.056 \\
\hline $\mathrm{N}$ & 7,258 & 5,849 & 4,645 \\
\hline \multicolumn{4}{|l|}{ Panel $\mathrm{C}: \leq 20$ miles } \\
\hline & $\begin{array}{c}0.063 \\
(0.056)\end{array}$ & $\begin{array}{c}0.153 * * * \\
(0.052)\end{array}$ & $\begin{array}{l}0.112^{*} \\
(0.060)\end{array}$ \\
\hline Mean dep. variable & 0.852 & 0.836 & 0.836 \\
\hline $\mathrm{R}^{2}$ & 0.037 & 0.036 & 0.042 \\
\hline $\mathrm{N}$ & 7,258 & 5,849 & 4,645 \\
\hline \multicolumn{4}{|l|}{ Panel D: $\leq 50$ miles } \\
\hline & $\begin{array}{c}0.043 \\
(0.045)\end{array}$ & $\begin{array}{c}0.102 * * \\
(0.041)\end{array}$ & $\begin{array}{c}0.078 \\
(0.049)\end{array}$ \\
\hline Mean dep. variable & 0.903 & 0.894 & 0.891 \\
\hline$R^{2}$ & 0.029 & 0.029 & 0.030 \\
\hline$N$ & 7,258 & 5,849 & 4,645 \\
\hline
\end{tabular}

NOTE: Each cell represents a point estimate and the standard error from a separate regression. Standard errors robust to heteroskedasticity and clustered by individual are in parentheses; each observation is a person-year. The dependent variable is a binary indicator for whether the mode of an individual's residential ZIP code in a year was within the specified distance (by panel) from Kalamazoo's central business district. ***, **, and * indicate statistical significance at the $0.01,0.05$, and 0.10 levels, respectively. Unlike Table 6 , the sample here is conditioned on at least one matched quarter per year.

SOURCE: Authors' calculations from KPS, NSC, and Michigan UI administrative data. 